21 (2013)

Les juristes et la hiérarchie des normes

Francesco Di Donato

\title{
La hiérarchie des normes dans l'ordre juridique, social et institutionnel de l'Ancien Régime
}

\author{
Warning \\ The contents of this site is subject to the French law on intellectual property and is the exclusive property of the \\ publisher. \\ The works on this site can be accessed and reproduced on paper or digital media, provided that they are strictly used \\ for personal, scientific or educational purposes excluding any commercial exploitation. Reproduction must necessarily \\ mention the editor, the journal name, the author and the document reference. \\ Any other reproduction is strictly forbidden without permission of the publisher, except in cases provided by legislation \\ in force in France.
}

revues.org

Revues.org is a platform for journals in the humanities and social sciences run by the CLEO, Centre for open electronic publishing (CNRS, EHESS, UP, UAPV).

Electronic reference

Francesco Di Donato, «La hiérarchie des normes dans l'ordre juridique, social et institutionnel de l'Ancien Régime », Revus [Online], 21 | 2013, Online since 01 March 2014, connection on 03 March 2014. URL : http:// revus.revues.org/2797; DOI : 10.4000/revus.2797

Publisher: Klub Revus - Center za raziskovanje evropske ustavnosti in demokracije http://revus.revues.org

http://www.revues.org

Document available online on: http://revus.revues.org/2797

This document is a facsimile of the print edition.

All rights reserved 


\section{La hiérarchie des normes dans l'ordre juridique, social et institutionnel de l'Ancien Régime}

Le contrôle de constitutionnalité, dont la magistrature parlementaire de l'Ancien Régime revendiquait le plein droit, nétait pas fondé uniquement sur les lois fondamentales du royaume, mais sur l'ensemble des principes («les maximes») tirés de la "Tradition ». Cette dernière était composée en premier lieu par le droit divin et le droit naturel, c'està-dire par des systèmes juridiques qui nécessitaient, tous les deux, une interprétation juridictionnelle « sapientiale ». Cette activité interprétative était « révélatrice » d'un corpus de valeurs métaphysiques à laquelle seule la Scientia Juris des magistrats pouvait puiser. Mais dans la sphère de la Tradition juridique rentraient aussi le " dépôt légal ", c'està-dire l'ensemble de toutes les lois, même des lois ainsi dites " ordinaires ", c'est-à-dire celles qui avaient été produites par la simple manifestation de volonté souveraine d'un roi prédécesseur " car tel avait été son plaisir» (formulation moderne de la maxime de droit romain : " quidquid principi placuit legis habet vigorem »). Ainsi la juridiction parlementaire donnait lieu à un jugement de constitutionnalité qui était normalement exercé de manière très flexible par le corps de la magistrature, dépendant des circonstances et des intérêts politiques momentanés des situations juridiques qu’elle voulait protéger. La hiérarchie des normes était ainsi un formidable instrument de protection de cet ordre juridique dont les legum doctores se sentaient les tuteurs. Elle était, donc, directement liée au gouvernement politique des juges.

Mots clés : hiérarchie des normes, Ancien Régime, cours de justice, magistrats, Parlements, contrôle de constitutionnalité, royauté

\section{QUESTION FONDAMENTALE ET ENJEU POLITICO-HISTORIOGRAPHIQUE}

Y a-t-il une hiérarchie des normes dans l'Ancien Régime ? Cette question historiographique, qui ne se prête guère à une mésentente, ${ }^{1}$ revêt la plus grande importance. Elle n'est pas rhétorique du tout, ni oisive, ni purement érudite, car de la réponse que l'on décide d'y donner dépend toute l'interprétation de l'ordre juridique et de la structure de la société avant la Révolution.

Par conséquent elle pourrait nous aider à expliquer beaucoup de choses sur la chute du vieil ordre et sur le bouleversement révolutionnaire, qui ouvre la porte à un nouveau système, à une nouvelle manière de concevoir le rapport entre droit et société, c'est-à-dire à une vision du monde qui est encore dans

* frdido@alice.it | Professeur d'Histoire des Institutions Politiques à l'Université de Naples “Parthenope" (Italie).

1 Dans le sens entendu et très finement expliqué par Rancière 1995. 
une large mesure la nôtre aujourd'hui. Il s'agit donc d'une problématique qui est fondamentale tant sur le plan historiographique que sur le plan de l'actualité politique tout-court.

L’enjeu historiographique posé par cette question de fond (peut-on parler d'une véritable hiérarchie des sources dans l'ordre juridique de l'État moderne, c'est-à-dire entre les XVème et XVIIIème siècles et pour certains aspects même avant?) concerne en premier lieu l'idée que l'on se fait de l'" État absolu », de sa légitimation, de ses structures institutionnelles et de leur fonctionnement, de leurs rapports avec le corps social, de leurs origines et de leur développement. ${ }^{2}$ En un mot, il s'agit d'aborder la reconstruction historique avec une méthode réaliste, ne visant pas uniquement les aspects juridiques formels, voire purement normatifs, mais focalisant l'attention sur les " relations effectives " (selon la célèbre expression de Roland Mousnier). ${ }^{3}$

Cela permet, entre autres, de vérifier constamment la façon concrète dont les normes se réalisent dans la réalité des comportements individuels et sociaux et, en sens contraire, de comprendre plus aisément le fondement social du droit et de l'ordre juridique qui s'instaure dans une société. Ce processus en double sens est ce que les historiens appellent solidarités verticales. ${ }^{4} \mathrm{Et}$ il faut mettre bien au clair dès maintenant que, dans la mesure où il $\mathrm{y}$ a une relation très stricte entre cette " verticalité » sociale et la hiérarchie du système juridique, il est indispensable de connaître la première pour bien comprendre la deuxième.

En outre, la réponse à cette même question détermine quelques implications elles aussi importantes, sur la comparaison que lon peut faire - qu'il est toujours utile de faire - entre passé et présent, c'est-à-dire entre des sociétés qui se situent sur des niveaux chronologiques et typologiques différents. Cela pourrait nous aider, à la fois, à expliquer pourquoi un changement s'est produit dans l'organisation du système politique et juridique, à quels besoins réels et profonds du corps social ce changement a répondu, ce qu'il voulait effectivement réaliser, pourquoi les énergies mentales et physiques ont été à un certain moment drai-

2 D’après la plus récente, approfondie et bien au courant historiographie médiéviste, le processus de formation de l'État moderne doit être anticipé au moins de deux siècles par rapport à la vision traditionnelle. L'État moderne est vu ainsi comme un organisme évolutif dont la structure embryonnaire se forme au cours de la période médiévale. Cette thèse avait été déjà formulée, dans ses grandes lignes, par Strayer 1970 et savamment reprise, avec une très fine analyse sémantique comparée, par Tenenti 1987. Pour l'historiographie française, cf. Krynen 1993 ; Rigaudière 2003. On ne peut pas se passer, sur cet argument si important, du monumental effort mené par plusieurs spécialistes coordonné par J.-Ph.Genet dans le cadre d'une importante A.T.P. du C.N.R.S., intitulée Genèse de l'État moderne, et qui a donné lieu à un grand nombre de publications très importantes: cf. Genet-Le Mené 1987 ; Genet 1990 ; Coulet-Genet 1990 ; Blockmans-Genet 1993 ; Reinhard 1996 ; Bonney 1996 ; Coleman 1996 ; Blickle 1998 ; Contamine 1998 ; Padoa Schioppa 2000 ; Ellenius 2001.

3 Cfr. Mousnier 1970a et (2002:5, 7 et 153).

4 Cfr. Mousnier 1970a et (2002: 5,7 et 153). 
nées vers l'irrésistible intérêt à la mutation. Cela pour dire que cette perspective méthodologique peut nous aider à formuler un schéma d'interprétation sur les motivations profondes pour lesquelles se produit le passage d'un monde à un autre, d'un système de valeurs à un autre, d'un ordre juridique et institutionnel à un autre.

Il y a un niveau de compréhension de la réalité historique (et pas seulement historique) qui reste interdit à une explication entièrement fondée sur la discontinuité, sur le passage brusque d'un système socio-politique à un autre. Le fétichisme de la coupure et de la discontinuité en histoire a fait son temps (et a produit bien des dommages!). Dans l'intelligence d'un phénomène historique il faut toujours se demander (car aucune société nest complètement indépendante de celle qui l'a immédiatement précédée et aussi de celles qui remontent encore plus en arrière dans le temps) : $:^{5}$ qu’est-ce qui a été sauvé, malgré la rupture?

Cette question croise aussi notre problème spécifique : est-ce que la hiérarchie des normes fait partie des choses qui ont été sauvées et, à la limite, mieux structurées, après le clivage révolutionnaire et dans l'organisation juridique, politique et sociale qui s'en est suivie ? Du point de vue de l'organisation des sources du droit, malgré les évidentes différences que l'on pourrait observer, le système de l'Ancien Régime, s'il est bien étudié et correctement interprété, peut-il être considéré comme une 'structure-mère', dont le développement a fait évoluer les choses dans le sens que nous connaissons de nos jours?

La thèse que jessaie de démontrer ici est fondée sur l'argument principal que le principe de la hiérarchie des normes, tel que nous le concevons aujourd'hui, était appliqué aussi dans l'Ancien Régime. Certes, personne ne nie que les conditions socioculturelles étaient à l'époque bien différentes des sociétés contemporaines, quoiqu'il s'agisse, si l'on regarde de plus près, plus de formes et de rites que de substance. Chacun peut se convaincre aisément que contrairement aux apparences - c'est-à dire si l'on n'en reste qu'à la mythologie, à la vitrine idéologique mise en place (comme dans tout régime politique dailleurs, chacun a la sienne) par les doctrines absolutistes ou, en contraste par rapport à elles, par les doctrines révolutionnaires - cétait proprement sur ce principe-pivot de la hiérarchie normative quétait fondée toute l'architecture juridique, politique et institutionnelle de l'État absolu.

Toute la question assume un sens très différent par rapport à ce que nous sommes habitués à penser (sur la base de la reconstruction historiographique traditionnelle), dans la mesure où on va procéder à une sérieuse déconstruction de l'image du roi absolu comme d'un monarque tout-court, réellement legibus solutus c'est-à-dire délié de toute loi, un souverain qui agit en dehors d'un ordre

5 Cf. Hadot (2006: 59 et 65). 
juridique et prend ses décisions - que l'on considère donc comme les seules lois du royaume - sans contraintes d’aucun genre. La réalité est bien différente de ce cadre que la lecture traditionnelle nous a transmis. ${ }^{6}$ Lordre juridique de la société que la Weltanschauung révolutionnaire a polémiquement décrit sous l'étiquette d' "Ancien Régime " était beaucoup plus complexe que le schéma centré sur l'identification totale entre la voluntas regis et la lex. Le système de l'État absolu prévoyait toute une série de contraintes et d'articulations que l'on a résumées sous le terme de " constitution ».7

Or, il est évident que la gestion de cette " constitution » ne pouvait pas être confiée au même pouvoir que ce réseau de contraintes avait la tâche de contrôler et limiter. Les «théories des freins » (dont celle de Claude de Seyssel qui est à juste titre la plus célèbre), c'est-à-dire l'autolimitation du souverain, ne pouvaient donner lieu à aucune pratique efficace. Bien avant Montesquieu, la réflexion juridique « constitutionnelle »- émanant quasi exclusivement du milieu judiciaire parlementaire - avait élaboré un système de contrepoids centré sur la fonction jurisprudentielle. La jurisdictio, confiée à la magistrature, assuma ainsi progressivement un rôle politique central dans les équilibres socio-institutionnels de l'État absolu. Le fonctionnement du système constitutionnel de ce dernier fut l'objet d'un conflit permanent entre le pouvoir politique centré sur la figure du monarque (dans la réalité concrète, sur l'action de l'appareil ministériel) et le contre-pouvoir judiciaire, qui avait la prétention de réaliser un contrôle, à plusieurs niveaux, de la fonction législative et gouvernementale. 8

Si l'on regarde les choses du point de vue exclusivement royaliste, on est tenté de conclure que l'idée même d'une hiérarchie normative était incompatible avec le schéma élémentaire "rex est lex", qui est à la base du processus de positivisation du droit et de la restriction de plus en plus marquée du droit coutumier non rédigé. ${ }^{9}$ La souveraineté absolue, dans la construction théorique du concept, ne pouvait quêtre fondée sur le principe de l'indivisibilité du pouvoir (selon la célèbre formule bodinienne) dont découlait le corollaire d’unicité de la loi. Le monopole du pouvoir législatif concentré dans les mains du roi - et seu-

6 Une véritable tradition historiographique décrit dans les détails le fonctionnement réel du système institutionnel de l'État absolu : Doucet 1948a et 1948b, Zeller 1948 ; Olivier-Martin 1948, 1988, 1997a, 1997b (qui était pourtant sur des positions idéologiques et historiographiques nettement conservatrices et peut-on dire philo-monarchique). Cette ligne d'interprétation avait déjà effrité le dogme de l'absolutisme entendu de la vieille manière. Ensuite, beaucoup de contributions ont définitivement démoli l'idée d'un absolutisme effectif et triomphant, en s'appuyant sur un grand nombre de données nouvelles : je ne citerai ici que Richet 1973 ; Mousnier 1974-1980 (le vrai champion de la démolition du paradigme absolutiste) ; et plus récemment Harouel et al. 1987 ; Sueur 1993 et 1994 ; Barbiche 1999 ; Saint-Bonnet \& Sassier 2004.

7 Cf. Mousnier 2002. Plus récemment, voir aussi la très efficace mise au point de Vergne 2006.

8 J'ai développé cette thématique dans mon ouvrage récent : Di Donato 2003a.

9 Cf. Rigaudière 2004. Voir aussi Krynen-Rigaudière 1992. 
lement du roi - était donc le pilier fondamental, voire le dogme insurmontable, de tout le système monarchique sur lequel insistait toute la doctrine politique élaborée par les partisans de la modernisation centrée sur le pouvoir du roi.

Identifiée avec la volonté du souverain, la loi royale était, selon cette doctrine, la seule source du droit positif et il n'y avait pas de place pour d'autres sources, ni subordonnées ni - à plus forte raison - concurrentielles ou supérieures. À lâge moderne le droit romain dans les régions du midi et la coutume dans le nord avaient été progressivement absorbés dans le droit positif royal et ne pouvaient en aucun cas être considérés comme des domaines ou des ordres juridiques alternatifs au droit du roi. ${ }^{10}$

L'idée de hiérarchie entre normes de différents niveaux était donc niée à la racine. Elle contrastait avec les fondements ultimes du système monarchique absolu dans lequel la souveraineté du roi était légitimée par le droit divin. Ce dernier est par définition unique et suprême, car il provient de Dieu. Il ne pourrait donc point admettre de normes alternatives à celles que Lui-même édicte. Ainsi l'absolutisme contient dans son esprit fondateur une raison foncière qui visait à tout niveler et tout réduire au monopole suprême de la loi. Il n’y aurait donc apparemment aucun espace pour une hiérarchie des normes.

Dès le XVIème siècle Bodin avait tracé la ligne théorique définitive : celui qui a le pouvoir de faire loi a tout le pouvoir ; le roi est le seul sujet qui a le droit de produire le droit, donc c'est lui qui a tout le pouvoir. « Faire loi » est resté pour longtemps, même dans l'imaginaire collectif de la société de l'Ancien Régime, la prérogative principale et exclusive du souverain. ${ }^{11}$ La volonté du roi - image vivante de celle de Dieu - étant la seule source du droit, la loi qui en dérivait était l'unique source des normes juridiques. Il n'y avait pas de hiérarchie possible, car celle-ci aurait présupposé plusieurs niveaux de production normative. Si la source de la production normative était au contraire unique, aucune hiérarchie nétait même clairement possible. Les deux modèles restent décidément antithétiques.

Et pourtant cette image du roi législateur unique et absolu - très utile sur le plan psychologique pour renforcer le lien social - ne correspondait point à la réalité effective de la vie politique et de lordre juridico-institutionnel et social de la monarchie absolue. " Faire loi » était, dès le Moyen Âge, un processus complexe dans lequel le roi ne rentrait que comme l'un des pouvoirs actifs. ${ }^{12} \mathrm{On}$

10 Cf. Piano Mortari 1962, 1977, 1980, 1989, 1991 ; Guizzi 1969, passim et spécialement 27 ; plus récemment, Rousselet-Pimont (2005 : 501-505 : «L'assimilation de la coutume rédigée à la loi »).

11 Cf. Richet (1973:25-26 et 53). Sur l'argument « Bodin et la loi comme acte typique de la souveraineté», voir aussi Goyard-Fabre 1989 ; Quaglioni 1992 ; Franklin 1993 ; Beaud (1994 : 27 198) ; Zarka 1996 ; Spitz 1998.

12 Cf. les deux belles et récentes recherches de Petit-Renaud 2001 et de Rousselet-Pimont 2005.

revue de théorie constitutionnelle et de philosophie du droit 
s'aperçoit facilement que cette fonction demeure de plus en plus entrelacée avec la fonction de juger, de « dire le droit ». La jurisdictio des magistrats se qualifie bientôt comme une pièce essentielle du pouvoir de " condere leges »; elle devient ainsi une véritable " sémantique du pouvoir politique ». ${ }^{13}$

Les juges allaient alors se considérer comme des vrais co-législateurs du royaume. ${ }^{14}$ Ils appuient cette prétention sur l'affirmation que la fonction de juger dérive d'une double représentation : le pouvoir juridictionnel est reconnu d'un côté par la volonté du souverain (mais cette « délégation » trouve sa source dans une volonté en quelque sorte obligée, car il ne peut pas administrer personnellement toute la justice dans un État si étendu),15 et, d'un autre côté, par communication divine directement adressée au jurisconsulte lui-même. ${ }^{16}$ Le juge devient ainsi un représentant immédiat de Dieu et par conséquent il va assumer naturellement la fonction de médiateur des volontés divines transférées dans le droit séculier, formellement prononcé par la bouche du roi. Ce dernier nest alors dans ce schéma que l'ordinaire «canal par lequel Dieu transmet la fonction de juger aux hommes » 17 par le biais de la science des juristes-magistrats.

Déjà au début du XIIIème siècle s’affirme « l'idée d’une justice [qui est] souveraine " à cause de son " essence divine ". ${ }^{18}$ Et cette " divinité » de la justice rentre dans la vie du royaume à travers l'indispensable intermédiation du corps - qui est un véritable corpus mysticum - des " savants " inspirés. ${ }^{19}$ Le droit se pose, alors, comme une véritable « exception » au savoir du prince. 20 Un savoir qui se veut de plus en plus indispensable pour penser et construire l'État ainsi que pour le gouverner. ${ }^{21}$ Dès le XIVème_XVème siècle le " rempart » de l'appareil d'État constitué par le " grand corps » de la magistrature parlementaire en robe acquiert son poids politique et institutionnel, progressivement plus puissant. ${ }^{22}$

\section{Costa 1969.}

14 Sur cet argument je me permets de renvoyer le lecteur à mon livre Di Donato 2003a.

15 Cf., sur la « justice déléguée » ou, au contraire, « retenue », Sueur 1993 et (1994: I, 144-145, 197, 229-232, 312 et 354-355 ; II, 162-181, 229, 246-268 et 278-279).

16 Cf. Renoux-Zagamé 2003 ; voir aussi, sur la relation atavique dans les sociétés indo-européennes entre droit et sacralité, Chiappini (2006 : 151-170), spécialement (pour ce qui concerne la " mobilisation des puissances divines au service de lordre juridique » et sur les "prêtres-magistrats » appelés à la gérer) dans le chap. I de la deuxième partie («Le sacré à l’ouvre dans le droit ").

17 Rousselet-Pimont (2005: 546).

18 Jacob (2001: 36 et 71) : " L'idée que la fonction de juger est d'essence divine et que, de cette essence, elle tire une part directe de souveraineté, indépendamment de la délégation que lui en confère le chef politique, traverse l'histoire de la justice depuis le Moyen Âge ».

19 Cf. Arnaud 1977.

20 Cf. Krynen 2002.

21 Cf. Rigaudière 2003. Voir aussi Padoa-Schioppa 2000 et 2003.

22 Cf. Autrand 1981. 
C'est à ce moment là que le magistrat commence à centrer son discours sur la valeur absolue et inattaquable de sa « conscience » sur lequel s'appuie le principe de la libera existimatio, le jugement " par intime conviction ", c'est-à-dire un forum de sa sphère personnelle qui devient le "trou noir " incontrôlable et par conséquent insaisissable de sa décision. ${ }^{23} \mathrm{La}$ construction de l'État en France emprunte ce passage dialectique crucial du renforcement (qui est aussi théologique qu'institutionnel) 24 de la structure des offices judiciaires, avec la constitution d'un corps toujours plus autonome - grâce aussi à la vénalité des charges et à leur transmissibilité par héritage 25 - dont la volonté de participation politique ne tardera pas à se manifester. ${ }^{26}$

\section{HIÉRARCHIE DES NORMES ET GOUVERNEMENT DES JUGES}

Dans cette transformation décisive de l'État moderne, les legum doctores, et notamment ceux qui étaient en charge de la juridiction suprême, procèdent à la construction d'un ordre juridique de fait dont le caractère essentiel était la structure hiérarchisée, tout en continuant à propager la doctrine monarchique absolutiste (qui leur était indispensable pour ôter le risque de républicanisme ${ }^{27}$ et pour éluder la responsabilité de l'appareil public). Celle-ci était en effet indispensable à l'exercice d'un contrôle de légalité constitutionnelle que les juristes des parlements pensaient comme instrument fondamental de participation à l'exercice de la souveraineté législative. Le but de cette opération complexe était clairement de limiter le pouvoir du souverain et de le situer à l'intérieur d'un réseau de contraintes juridiques dans lequel l'interprétation juridictionnelle pouvait jouer un rôle déterminant. ${ }^{28}$

23 Cf. Carbasse-Depambour-Tarride 1999.

24 Ecole française de Rome 1991.

25 Cf. le volume classique de Mousnier 1971. Voir aussi, plus récemment, la perspective de Descimon 1990 et de Nagle 2008.

26 Cf. Richet 1973 ; Mousnier 1970a et 1974-1980.

27 Les juristes de l'Ancien Régime craignaient énormément l'instauration d'un régime républicain car, comme l'expérience en Europe - et notamment dans l'Italie du nord - le leur montrait, le pouvoir de la médiation patriarcale des legum doctores était pratiquement annulé. On peut en voir un exemple dans le journal du voyage italien de Montesquieu, notamment dans le jugement opposé qu'il porte sur les deux villes de Gênes (républicaine) et de Naples (monarchique-'absolutiste'). Contrairement à ses prémisses (il adresse des louanges à la beauté du paysage urbain gênois et au contraire il juge négativement le désordre chaotique napolitain) il exprime un jugement défavorable sur le premier système et enthousiaste sur le deuxième. Je renvoie pour l’analyse plus détaillée de ces aspects à mon essai Di Donato 1998 b.

28 Pour approfondir l'argument des « contraintes juridiques » sur le plan plus proprement théorique, voir le livre collectif dirigé par Troper et al. 2005. Troper, lui-même, applique dans le volume cette théorie à une situation historique bien déterminée, telle que la Constitution de 
Il ne faut jamais oublier que dans la doctrine ainsi que dans l'action stratégique de la robe parlementaire il y avait ce double aspect : d'un côté les juristes proclamaient la nécessité de concilier souveraineté royale et juridiction ; mais d'un autre ils ne visaient à l'affirmation (cette fois-ci réellement 'absolue') de la loi interprétée par eux-mêmes qu'à travers les actes (pas nécessairement les actes officiaux) du Parlement. ${ }^{29}$ Ce dernier prétendait se mêler (l'expression que l'on trouve dans les sources historiques est précisément "s'immiscer») des affaires de l'État et notamment dans la procédure de formation des actes législatifs. Puisque ce pouvoir était une prérogative exclusive du roi, car autrement on n’aurait plus parlé de monarchie, les robins étaient les premiers à déclarer leur indisponibilité à assumer directement le pouvoir législatif. Il fallait alors trouver un moyen de sauver le principe formel monarchique et le pouvoir substantiel de la magistrature. Cette contradiction fut résolue à travers l'idée d'un contrôle exercé par la magistrature parlementaire sur les actes du roi, voire de ses ministres, souvent considérés comme corrompus et peu fiables.

La hiérarchie des normes était donc directement liée à la naissance de ce contrôle de légalité que seuls les juristes pouvaient mettre en œuvre. L'enjeu était donc la légitimité du corps de la magistrature c'est-à-dire du pouvoir juridictionnel de participer activement à la vie de l'establishment de gouvernement et aux processus de décision politique, à commencer par la formation de la loi.

La doctrine juridique fut alors appelée à jouer son rôle. Voici donc fleurir les traités sur les « freins » (Claude de Seyssel, 1519), ou les théories sur le droit divin, sur la loi de nature et sur les lois fondamentales (Charles Loyseau, 1608), ou sur l'autorité du Parlement en matière de jurisprudence politique (Jean Montaigne, 1512 ; et plus tard, en 1617, La Roche Flavin). ${ }^{30}$ Qu'elle le dise de façon explicite ou non, le but de toute cette copieuse littérature juridique et politique à la fois est toujours le même : affirmer qu'il y a plusieurs sources du droit, que ces sources sont disposées selon une hiérarchie normative et que cette hiérarchie donne lieu eo ipso à un contrôle de conformité. Ce contrôle doit

l’an III (1795). Les juristes de l’Ancien Régime ont essayé de construire autour du roi et de son gouvernement (un système monarchique que, pour d'autres raisons, eux-mêmes aimaient définir 'absolu') ce réseau de contraintes pour produire une situation de droit et de fait dans laquelle, malgré le fait qu'il n'y avait pas « d’obligation (au sens technique de prescription) » et, à la limite, qu'il n'y avait pas du tout « de contraintes imposées », toutefois « la configuration du système juridique é[tait] telle qu’elle cré[ait] une situation objectivement contraignante ». Cette stratégie des juristes trouvait dans la hiérarchie normative un pivot fondamental. Par conséquent, on peut bien dire que, grâce notamment à ce système hiérarchisé des sources du droit, les choix du roi et de ses ministres étaient, selon la magistrature, souvent « limités, ou parfois inexistants» (Troper et al. $2005: 42$ ). C'est ainsi que les juristes des parlements ont pu créer des "maximes de droit public », telles que « le roi règne mais il ne gouverne pas », ou "le roi se trouve en France dans une heureuse impuissance ".

29

Cf. Di Donato (2003 : chap. II, $\$ \$ 25-26,326-336)$.

30 Montaigne 1512; Seyssel 1519; Loyseau (1608: II, \$\$ 1- 9); La Roche Flavin 1617. 
être réalisé par le Parlement en tant que cour de justice suprême du royaume à laquelle Dieu, lui-même, a confié la tâche d'aider le pouvoir du souverain à demeurer dans le juste sillon de la légalité divine et naturelle et dans le respect des lois fondamentales du royaume. ${ }^{31}$

On met ainsi en place une échelle de valeurs normatives dont le résultat principal est d'affirmer que le pouvoir et l'autorité du roi ne sont légitimes que s'ils ne sont pas en conflit avec l'ordre juridique supérieur. Cet ordre est, justement, objectif, et du coup il est supérieur même au roi. La volonté de ce dernier doit donc s'y conformer et par conséquent on affirme que l'État est l'entité suprême, en tant qu'il incarne une valeur et un intérêt qui sont supérieurs à tout, monarque y compris, de même que les lois constitutionnelles sont supérieures aux lois ordinaires. Ces dernières, émanant du pouvoir législatif, ne pouvaient point abroger celles-là, ni les modifier, ni même les intégrer. ${ }^{32}$

Le souverain et la monarchie étaient les instruments pour la réalisation de l'État. Ils nétaient pas le but, mais le véhicule privilégié à travers lequel on assurait la vie civilisée et l'ordre politique et social voulu par Dieu lui-même. Il fallait donc une hiérarchie des sources normatives pour garantir la conformité du comportement du roi très chrétien et de ses décisions à cet ordre supérieur, divin et naturel qui formait l'essence ultime, la Ratio fondamentale de l'État.

Les magistrats et plus généralement les juristes pensaient que la justice ne pouvait être assurée que si "à l'occasion de chaque jugement » les juges mettaient «à exécution les lois qui exprim[aient] la volonté du Créateur». Ainsi les arrêts étaient considérés par les jurisconsultes qui les tiraient des « commentaires de la loi divine ». Et la justice - disait-on - nétait que « la sœur de la religion et de la nature divine de la loi ».33 L'ordo juris était, en somme, conçu par ses «juges-prêtres» comme une véritable « théocratie judiciaire ».34

Ce principe de fond, que les juristes français ont depuis toujours considéré comme le noyau dur de lordre non seulement juridique mais providentiel du royaume de France, est énoncé de façon limpide dans une grande quantité de sources textuelles. Parmi les plus représentatives d'entre elles, il y a une fameuse harangue de l'un des plus célèbres magistrats de son temps, Achille de Harlay, premier président du Parlement de Paris, au lit de justice du 15-16 juin 1586. En parlant en présence du roi Henri III, il utilisa des mots qui, même pour nous, ne peuvent prêter à aucune équivoque :

31 Outre l'ouvrage classique de Lemaire 1907, cf. plus récemment Saguez-Lovisi 1984.

32 Cf. Mousnier (2002: 133).

33 Sur l'identité divine de l'ordre juridique de l'Ancien Régime et sur les complexes problématiques déterminées (entre autres sur la mentalité et la Weltanschauung des juristes) par cette conception théologico-politique, cf. le très beau livre de Renoux-Zagamé 2003 (les citations dans le texte sont à la p. 175).

34 Renoux-Zagamé (2003 : 121-129). 
Nous avons, Sire, deux sortes de loix, les unes sont les loix et ordonnances des rois, qui se peuvent changer selon la diversité des temps et des affaires; les autres sont les ordonnances du royaume, qui sont immuables et inviolables, et par lesquelles vous êtes monté au throsne royal, et à cette couronne été conservée par vos prédécesseurs jusques à vous. /.../ Celle là entre autres est une des plus saintes, et laquelle vos prédécesseurs ont plus religieusement gardée, de ne publier ni loi ni ordonnances qui ne fût vérifiée en cette compagnie. Ils ont estimé que violer cette loi, cétait aussi violer celle par laquelle ils sont faits rois. /.../ [Ain]si devez-vous observer les loix de l'Estat du royaume, qui ne peuvent estre violées sans révoquer en doute votre propre puissance et souveraineté. 35

De Harlay expose ici une vraie hiérarchie des sources du droit en vigueur dans le royaume. Les normes du niveau supérieur étaient inviolables et immuables. Il va de soi que dans son arrière-pensée cétait uniquement la jurisdictio du Parlement, magistrature suprême du royaume, qui avait la tâche de préciser, au fur et à mesure des situations qui se présentaient, l'ampleur de ces principes fondamentaux et leur application effective.

Ce pouvoir nétait pas délégué par le roi, mais dérivait directement du munus insufflé d'en Haut à chaque magistrat par le biais de la Scientia juris qui était justement, comme cela se retrouve dans le fragment d'Ulpien reçu dans le Digeste, considérée comme une science " des choses divines et humaines ». 36 C'est précisément par cette raison qu'il met en liaison la hiérarchie des normes, qui était un état de fait objectif, un status quo voulu par la nature divine et du coup non

35 Ce discours du président de Harlay a été interprété, par la quasi totalité des historiens qui s’en sont occupés, comme une défense acharnée de l’enregistrement parlementaire, négligeant ainsi, presque complètement, l'aspect - qui, à mon avis, est au contraire lélément décisif concernant la hiérarchie des sources du droit : cf. Lemaire (1907 : 148-149) ; Doucet (1948 a: 66) ; Richet (1973 : 27-28) ; Olivier Martin (1997a : 8). Soulignant comme, à propos du prétendu lit de justice du 15 ou 16 (la date est incertaine) juin 1586, la source primaire de toute historiographie ne sont pas les registres du Parlement (c'est-à-dire une source officielle et institutionnelle), mais « un recueil de discours préparés pour l'occasion et rassemblés par le conseiller au Parlement Guillaume du Vair (1560-1621), Sarah Hanley a avancé l' « hypothèse vraisemblable que ces discours de 1586 » furent ou «prononcés au cours d'une réunion du Conseil royal à laquelle participaient plusieurs parlementaires, dont le premier président » (ils ne constitueraient donc pas un lit de justice, lequel n'eut pas du tout lieu), ou mieux encore qu'ils ne furent " jamais prononcés » tout en restant " dans les papiers de Guillaume du Vair » qui les avait déjà transcrits à l'avance : Hanley (1991 :211-212); cf. du Vair 1641. Quoi qu'il en soit, ce qui importe le plus est le fait que ces discours circulaient sous une forme ou sous une autre, plus ou moins officielle, et qu'ils constituaient le noyau dur de la vision politique et institutionnelle de la robe, formant un pilier de la Weltanshauung des juristes d'Ancien Régime. Lélément à mon avis fondamental qu'il faut saisir dans le discours du président de Harlay nest pas la défense de l'enregistrement tout-court, comme Leit-motiv de la rhétorique robine, mais l'importance qu'il donne à la hiérarchie normative comme fondement de toute l'architecture des prérogatives parlementaires en matière de politique.

36 D. I. I. I. 2: « Iuris prudentia est divinarum atque humanarum rerum notitia, iusti atque iniusti scientia »; cf. aussi Institutiones, I. I. I. Le célèbre passage est l'objet d'un pointu commentaire de Kantorowicz (1957 : ch. IV, \$2, 119 de l'édition italienne consultée). 
modifiable par la volonté humaine, avec la nécessité de donner une forme institutionnelle à l'application concrète de cette hiérarchie. Le contrôle parlementaire sur la législation royale - c'est-à-dire la vérification sur la compatibilité de la source de deuxième niveau avec la source supérieure - dont l'enregistrement constituait le pilier, nétait par conséquent que cette procédure, indispensable pour réaliser pleinement l'essence idéale du royaume et respecter la suprême Voluntas du Tout-Puissant. ${ }^{37}$

Lexistence d'un « corps » ou système de normes que ni le pouvoir du roi ni, a fortiori, aucun autre pouvoir étranger à la souveraineté nationale ne pouvait modifier, représentait aux yeux des jurisconsultes et notamment des magistrats munis de jurisdictio la plus crédible garantie de la stabilité de lordre juridique et social de la France, État de droit et non monarchie arbitraire. L'existence d'un Parlement et non d'une simple cour de justice était légitimée justement par ce fondement conceptuel : à côté d'un " corps " structuré de normes il fallait un " corps » institutionnel composé de sujets inspirés par la Science supérieure du droit qui étaient à même de réaliser un contrôle sur la législation royale et assurer quelle ne déborde pas de ses limites naturelles établies par la loi divine, par le droit de nature et par les lois fondamentales.

Les juristes insistaient beaucoup sur ce point crucial. Ils en faisaient la vraie spécificité de la civilisation que l'État monarchique français prétendait représenter au plus haut niveau de perfection. Au delà de ces "saintes et sages règles " - disaient-ils - il n'y avait que la barbarie. C’est ce qu'affirmait, par exemple, Du Vair :

Nous estimons que les Estats sont les principaux et excellens ouvrages de Dieu, sans la conduite et providence duquel jamais les esprits de tant d'hommes desbordez et inclins à licence, ne se laisseroient assembler et estreindre soub le lien d'une seule loy et d'un seul prince. 38

Si nous voulions utiliser les catégories conceptuelles et par conséquent le langage du droit contemporain nous devrions en conclure que le discours du président de Harlay atteste, en somme, de l'existence d'une constitution rigide au plus haut degré, au point quelle ne pouvait être modifiée par aucun pouvoir, fût-ce même un pouvoir constituant. Celle qui régissait l'État absolu était, donc, une constitution impossible à modifier sur le plan formel. Lévolution du droit était alors assurée par d’autres voies et avec d’autres moyens (essentiellement à travers les subtilitates de l'interprétation réalisées par la jurisprudence parlementaire) qui nétaient pas nécessairement institutionnalisées. ${ }^{39} \mathrm{Il}$ y a un "non-dit »-d'une importance fondamentale - dans le discours juridique (de l'Ancien Régime ainsi que de notre actualité) qui consiste essentiellement dans

37 Sur l'enregistrement, cf. Di Donato (2003a : 470-485).

38 Texte tiré des CEuvres de Du Vair (cf. Du Vair 1641) et cité par Lemaire (1907 : 143).

39 J'ai traité cet important problème dans mon essai : Di Donato 2007. 
le présupposé qu'il n'y a aucun contrôle possible entre les sources normatives de différents niveaux en dehors d'un processus d'interprétation. 40

Le témoignage du président de Harlay n'est pas l'élucubration isolée d'un intellectuel radical ou d'un outsider; il est au contraire l'analyse méditée d'un homme de l'appareil d'État - au plus haut niveau - qui était (et se sentait) l'héritier d'une longue élaboration doctrinale à laquelle avaient participé, dans des proportions diverses, juristes, philosophes et politiques issus de traditions différentes et d'idéologies variées. La conception de fond exprimée par de Harlay était donc très représentative de l'humus idéologique qui caractérisait la vision du monde et le modèle de l'ordo juris conçu par les juristes. La formule de Harlay devint immédiatement un topos du discours juridique qui ne fut jamais plus abandonné jusquà la Révolution et même au-delà d’elle.

Dès lors les magistrats des parlements allaient la considérer comme " une maxime liée à la constitution de la monarchie, pratiquée dans tous ses âges ». Encore en mars 1768, en pleine bagarre entre Parlement et Couronne, on la retrouve fréquemment utilisée par les robins, dans de nombreux documents. Un texte exemplaire à cet égard est représenté par les " cahiers » parlementaires du conseiller Glandres de Brunville. ${ }^{41} \mathrm{Et}$, à plus forte raison, pendant les «troubles » de la « réforme » du chancelier Maupeou la formule-Harlay devint dans l'intention des robins opposants un rempart formidable contre le bouleversement mis en œuvre par le gouvernement. On la retrouve citée - avec quelques adaptations mais en réalité telle quelle - dans les célèbres Principes avoués et défendus par nos pères de Louis-Adrien Le Paige, l'avocat et bailli du Temple, leader de la robe parlementaire, ${ }^{42}$ qui la considère comme l'une des maximes fondamentales de la constitution du royaume l' "une des plus saintes et que vos prédécesseurs ont plus religieusement gardée $» .43$

La distinction entre « lois fondamentales » et « lois ordinaires » forma, donc, un lieu commun de la littérature juridique et du langage typique des doctrines

40 Je renvoie, sur ce concept, aux ouvrages fondamentaux de Troper 1994, 1996, 1999, 2001 et 2003.

41 Bibliothèque du Sénat, fonds Boissy d’Anglas, vol. 803, f. 347 .

42 Cf. pour le profil de ce personnage, dont j’ai essayé de mettre en relief dans plusieurs ouvrages l'importance capitale pour l'entière politique du royaume (je ne renvoie ici quà Di Donato 2003 a et 2003b), la très récente entrée homonyme rédigé par R. Scialom, dans le Dictionnaire historique des juristes français : Arabeyre-Halpérin-Krynen (2007 : 492-493).

43 Cfr. Le Paige (1771 : ff. 23-24) : « Nous avons, Sire, deux sortes de loix ; les unes sont les ordonnances des rois qui se peuvent changer selon la diversité des temps et des affaires; les autres sont les ordonnances du royaume qui sont inviolables, par lesquelles vous êtes monté au trône royal, et cette couronne a été conservée par vos prédécesseurs jusqu’à vous ; celle-là entr'autres est une des plus saintes, et que vos prédécesseurs ont plus religieusement gardée, de ne publier ni loi, ni ordonnance qui ne fussent vérifiées; ils ont estimé que violer cette loi, cétoit aussi violer celle par laquelle ils sont fait rois, et donner occasion au peuple de mécroire de leur bonté» (les italiques sont dans le texte originel). 
élaborées par les juristes. Bref, elle fut considérée comme une notion juridique qui ne pouvait pas être négligée dans toute analyse théorique ainsi que dans toute action politique. Ni Pasquier, ni Bodin, ni même Cardin Le Bret - qui ne furent certainement pas parmi les ardents défenseurs de la ligne stratégique de la robe - n'auraient plus remis en cause cette vision des choses.

\section{LA HIÉRARCHIE NORMATIVE COMME INSTRUMENT TECHNIQUE DE LA POLITIQUE OCCULTE DU DROIT MENÉE PAR LA MAGISTRATURE}

A l'opposé de ce que ces très nombreuses sources textuelles nous montrent si clairement, la doctrine juridique traditionnelle et l'historiographie du droit (qui se veut un support de celle-là et qui par conséquent a renoncé à son rôle critique) sont pour longtemps restées liées à l'idée qu'un «droit supérieur»-c'està-dire une hiérarchie des sources juridiques - serait en contradiction, encore au XVIIIème siècle, avec « l'absolutisme de la loi, expression de la souveraineté » totale et indivisible du monarque. ${ }^{4}$

L'idée de la loi comme véhicule unique de la simple voluntas principis serait donc en irréductible conflit avec l'idée de la hiérarchie normative. Les « lois du roi » (pour reprendre la formule devenue usuelle grâce au titre d'un livre justement fameux de François Olivier-Martin) ${ }^{45}$ étaient les seules sources du droit dans l'État absolu. "Quidquid principi placuit legis habet vigorem » : il n'y avait que la volonté du roi qui pouvait être identifiée avec la volonté législative contenue dans la norme de droit. On accorde ainsi un très grand crédit à la formule qui clôt (et qui légitime) les actes royaux : " Car tel est notre plaisir ». La simple manifestation de la volonté du souverain était considérée comme loi de l'État. Cela veut dire que la négation de l'existence d'une hiérarchie des normes dans le système juridique de la monarchie absolue était conceptuellement en liaison avec l'image du roi comme pivot de l'État.

On affirmait par cette voie une conception de la souveraineté entendue comme attribution réelle de la personne du roi. Le pouvoir souverain s'incarnait dans le corps du roi. Et le roi était l'État. Voilà la formule qui expliquerait la structure socio-politique de l'Ancien Régime et l'opposerait au régime constitutionnel inauguré par la Révolution. ${ }^{46}$

44 Cf. Favoreu et al. (2003: 237-238).

45 Cf. Olivier Martin 1997a.

46 Sur le concept de «souveraineté » il y a eu récemment une floraison d'essais qui ont remis en cause plusieurs idées reçues. On ne signalera ici que : Cazzaniga-Zarka 2001; Barberi 2002 ; Ferrajoli 2004 ; Quaglioni 2004. 
Dans l'Ancien Régime manqueraient, donc, selon cette vision traditionnelle, les présupposés essentiels d’une hiérarchie des sources du droit. Par conséquent, on ne veut/peut pas reconnaître l'existence d'un contrôle de constitutionalité sur les lois du souverain. Et, de même, on ne reconnaît pas le rôle politique de la magistrature parlementaire. Les textes produits par la plume des juristes et notamment les documents de la juridiction des parlements (remontrances, arrêts, arrêtés, arrêts de règlement) ne sont considérés que comme des vaines " protestations » sans effet provenant d'un milieu d' « enragés » qui n’ont, au delà des mots qu'ils prononcent, flatus vocis, aucune influence sur la vie politique et sur les affaires de l'État.

On se débarrasse vite du discours parlementaire en le réduisant à une « rhétorique " vide et plaintive. 47 On est arrivé à dévaloriser à tel point l'action politique des parlements que l'on a considéré leur groupe comme rien d'autre qu' " un parti évanescent " voué à fondre comme neige au soleil ; leur stratégie politique est vue comme une faillite destinée à produire tout au plus des victoires "à la Pyrrhus »; leur discours politique et leurs doctrines juridiques tellement inconsistants qu'ils étaient totalement auto-référéntiels : le Parlement « parle pour faire exister ce dont il parle ». 48

Est-ce que les choses peuvent réellement être interprétées ainsi ? Pouvonsnous accepter passivement cette vision des choses qui nous a été léguée par l'historiographie traditionnelle ? Sur la base de preuves textuelles écrasantes et de nouvelles recherches menées par plusieurs études qui se sont progressivement intensifiées à partir des années 1960 jusqu'à nos jours, suivies d'une réflexion historiographique plus mûre et pondérée, la réponse à cette question doit être à mon avis : décidément non. Partons des sources des contemporains (c'est toujours la meilleure méthode dans les disciplines historiques de laisser parler d'abord les protagonistes de la vie politique, juridique et institutionnelle de l'époque que l'on veut étudier et reconstruire). Après ce passage fondamental de reconnaissance des sources on passera à l'étude des principales formules doctrinales et on essaiera de découvrir ce qui se cache sous celles-ci.

Nous allons considérer, d'abord, un discours prononcé par le chancelier de France François Olivier au Parlement de Rouen en Octobre 1550.49 Dans ce texte, le chancelier, juriste reconnu, identifie toutes les affaires d'État avec ce qui appartient « au public et à l'universel ».50 Avec cette expression il entendait transférer le discours du plan historique et politique à une dimension juridique et métaphysique destinée à favoriser une vision charismatique et ésotérique du pouvoir fondé sur les « lumières » de la Scientia juris.

47 Cf. Levinger 1990.

48 Cf. Maire (1998: 371, 396, 521).

49 Cf. Proposition faicte en la Court de Parlement de Rouen... (= BNF, inv. Lf-25. 127).

50 Proposition faicte en la Court de Parlement de Rouen... (= BNF, inv. Lf-25. 127). 
La présence institutionnelle de la "Compagnie », c'est-à-dire de la magistrature parlementaire, avait garanti l'unité de la juridiction souveraine, le seul pouvoir de l'État légitimé à unir « les matieres d'Estat et les causes de iustice de grande importance ».51 La souveraineté juridictionnelle du Parlement était nécessaire pouyr mettre fin à l'incontrôlable prolifération des « oppinions [sic] en toutes matières, tant civiles que criminelles ».52 Cela pouvait avoir lieu sans ôter la liberté des suffrages des magistrats.

Lentrelacement des deux sphères - droit et politique - ne pouvait se réaliser quà condition de faire rentrer dans le processus de formation/application de la loi la magistrature parlementaire. Et comment cela aurait été possible sans créer une hiérarchie entre différents niveaux normatifs ? Établir une hiérarchie des normes était donc un passage logiquement propédeutique à une participation légitime du Parlement à la formation de la loi, sans que cela puisse être considéré comme un bouleversement du principe fondamental de la monarchie absolue, c'est-à-dire l'unicité et l'indivisibilité de la souveraineté dans la personne du roi. Par l'effet de la hiérarchie des normes, le Parlement pouvait rentrer dans le jeu politique à travers le contrôle préventif de la légalité des actes royaux, tout en respectant formellement la liberté du souverain de choisir la formule adoptée dans le texte de loi proposé au Parlement pour la vérification.

C’est en raison de cet aspect que la monarchie française - considérée comme une forme de gouvernement dans laquelle pouvait s’affermir un équilibre institutionnel de fait qui voyait la haute magistrature jouer un rôle important - est interprétée par le chancelier Olivier « comme [voie] moyenne entre deux [systèmes] », tous deux excessifs, de la république et de la tyrannie. Grâce à l'existence du Parlement, on réalisait en France un procès équilibré dans lequel on sauvegardait le droit de chaque juge d'exprimer librement, voire sans contrainte politique d'aucune sorte, sa " propre raison ", mais en même temps on exigeait des garanties précises " pour cognoistre la preud'hommie des oppinans ».53 Le Parlement était donc un pouvoir qui produisait « autant de liberté et de secret, qu'en homme de bien en peult desirer $» .54$

Dans cette esquisse de la forme parfaite de l'État, les contrepoids à la puissance des magistrats ne manquaient pas. Comme ils avaient droit à la pleine autonomie dans leur jugement, ils devaient respecter « les ordonnances du Roi /.../ car faisant autrement serait plus tost une assemblée de gens facétieux que un légitime Sénat $» .55$

51 Proposition faicte en la Court de Parlement de Rouen... (= BNF, inv. Lf-25. 127).

52 Proposition faicte en la Court de Parlement de Rouen... (= BNF, inv. Lf-25. 127); dans le texte " manieres », mais la faute de frappe est évidente.

53 Proposition faicte en la Court de Parlement de Rouen... (= BNF, inv. Lf-25. 127).

54 Proposition faicte en la Court de Parlement de Rouen... (= BNF, inv. Lf-25. 127).

55 Proposition faicte en la Court de Parlement de Rouen... (= BNF, inv. Lf-25. 127). 
La préoccupation constante de maintenir léquilibre entre les différents centres de l'autorité publique avait induit Olivier à concevoir une hiérarchie précise des sources juridiques. Au sommet de cette pyramide, outre naturellement le droit divin et les lois fondamentales, il voyait la "coustume » et un peu plus bas la « loy » et les « ordonnances du Roy », qui pouvaient être « extorquées par importunité et circonvention et contre la perpetuelle intantion [sic] du Roy ».56 La Scientia juris des magistrats, se présentant comme un savoir impartial, avait toutefois pour tâche de préserver cet équilibre et de montrer d'abord au roi, mais aussi à tout le monde, les distorsions auxquelles une volonté souveraine arbitraire et sans freins pouvait parvenir.

Aux juges, toutefois, appartenait le devoir de formuler l'interprétation correcte et légitime de la volonté souveraine, car cétait la seule manière d'" acquicter la conscience du Roy » et celle des magistrats eux-mêmes. ${ }^{57}$ Mais, là aussi, il s'agissait d'une subtilité qui ne pouvait que très difficilement être utilisée pour acculer politiquement la magistrature. C'est vrai qu'en principe les juges ne pouvaient " jamais aller contre les termes [de la loi] et le sens évident quelle présentait, sous prétexte de l'interpréter ».58 Mais c'est aussi vrai que les instruments très raffinés de la technique exégétique et l'habileté consommée des sacerdotes juris avaient régulièrement raison de toute volonté royale textuellement exprimée. Il n'y avait point de textes tellement clairs, des formulations tellement « évidentes » qui ne pouvaient être manipulés par l'interprétation des jurisconsultes.

Les robins opéraient, partant, sous le bouclier du principe de légalité. C'était l'incontestable force qu'ils réussissaient savamment à faire valoir sur l'échiquier politique et dans les relations institutionnelles complexes qu'ils entretenaient avec la couronne. Grâce à la maîtrise de cette technique herméneutique savante et prudente, les decisiones parlementaires pouvaient aller jusquà contredire la volonté législative du souverain en la renversant justement et paradoxalement au nom du respect de la légalité. Regardons, à cet égard, le texte très clair des Monumens précieux de la sagesse de nos rois, allégué comme pièce justificative à l'une des plus célèbres remontrances de l'histoire parlementaire, celle du 9 avril 1753:

En refusant dobéir à ces ordres irréguliers, les magistrats ne font que satisfaire aux ordonnances, qui sont les volontés constantes et immuables du souverain, et préférer entre deux ordres contraires celui que lui-même ordonne de préférer ; /.../ ils ne pourroient agir autrement sans être vraiment désobéissans au roi, infracteurs des ordonnances et parjures, sans trahir le bien public, lordre de la justice, leur conscience, et un serment qui leur est commun avec le prince. /.../ Il seroit absurde de regarder lob-

56 Proposition faicte en la Court de Parlement de Rouen... (= BNF, inv. Lf-25. 127).

57 Proposition faicte en la Court de Parlement de Rouen... (= BNF, inv. Lf-25. 127).

58 Cf. Olivier-Martin (1997a : 411). 
servation de ces loix comme un combat entre le souverain et le magistrat; celui-ci ne diminue rien de son respect, de sa soumission et de son attachement inviolable à son souverain, qui sont les attributs et l'essence même de la magistrature : en se refusant à une obéissance perfide, il obéit réellement d’une autre façon ; ce n'est point l'autorité qu'il combat, c'est l'importunité dont elle est assiégée ; lorsqu'il rend le Trône inaccessible à toute injustice, il remplit le voeu du législateur. Nos rois nont jamais cru en descendre, en y faisant monter la Justice ; ils se sont toujours fait gloire de la prendre pour compagne, sedis assistricem. ${ }^{59}$

Il résulte donc, à l'évidence, que les juristes utilisaient la hiérarchie normative comme l'instrument principal de la médiation patriarcale c'est-à-dire comme le fondement du pouvoir politique intrinsèque à l'activité juridictionnelle. 60

La hiérarchie des normes était ainsi directement au service du gouvernement politique occulte des juges. Elle était le présupposé soit du discours doctrinal soit de l'action institutionnelle. Disposer d'une échelle hiérarchique de valeurs juridiques rendait beaucoup plus aisée la transformation du pouvoir juridictionnel en action politique, par le biais de la fonction d'interprétation. Cette velléité de conversion de la jurisdictio en puissance de gouvernement occulte était (et reste) la plus ancienne des prétendues prérogatives de la magistrature. ${ }^{61}$ Elle provenait de la conviction, déjà médiévale, qui était inculquée aux juristes dès la période de leur formation dans les écoles de droit, quà travers l'interprétation des textes normatifs le corps des juris periti pouvait construire un pouvoir scientifique inattaquable et invincible et surtout voué à jouer un rôle politique occulte et par conséquent sans responsabilité. 62

\section{LA HIÉRARCHIE NORMATIVE COMME FONDEMENT INDISPENSABLE DU CONTRÔLE PARLEMENTAIRE DE CONSTITUTIONNALITÉ}

Il est clair pourtant que, comme le principe hiérarchique des normes juridiques situait la loi du roi à un niveau bien inférieur au droit divin, à la loi de nature et aux lois fondamentales, elle impliquait aussi une hiérarchie des institutions judiciaires et politiques dans l'État absolu. ${ }^{63}$ Mais cette hiérarchie effec-

59 Cf. Monumens précieux de la sagesse de nos rois (= BNF, F-25312-25313), " Avertissement ", 5; cf. Di Donato (1996 : II, 567- 647 pour le commentaire de la remontrance, 647- 664 pour l'analyse détaillée des Monumens précieux et 1050-1051 pour le texte du document).

60 Sur la notion de "médiation patriarcale », je renvoie à mon essai Di Donato (2001: spécialement 100-102); voir aussi Di Donato 2006.

61 Sur cette persistance de longue durée de l'esprit de gouvernement inhérent au corps de la magistrature, cf. Di Donato 2006.

62 Cf. Costa 1969; Ajello (1999 : spécialement 325) ; Di Donato 2001.

63 Cf. Mousnier 1974-1980.

revue de théorie constitutionnelle et de philosophie du droit 
tive nétait pas évidente ; elle était, pour ainsi dire, renversée par rapport à ce que la réalité apparente faisait voir et même devait faire voir.

La hiérarchie normative était une structuration de l'ordo juris que les juristes des parlements considéraient comme indispensable pour réaliser de fait la soumission du droit positif royal au droit jurisprudentiel créé par la jurisdictio du Parlement. Le véritable but caché de la magistrature, comme on lit dans un manuscrit du XVIIIème siècle provenant de l'entourage du Grand Conseil, était de construire de façon occulte " une autorité au dessus de celle du roy même ", ce qui, dans un système monarchique paraît une évidente " absurdité ».64 Pour réaliser ce dessein, la hiérarchie des normes se révéla l'instrument le plus efficace.

\subsection{La mise en place d'un paradoxe politique : la hiérarchie normative comme instrument parlementaire de la royauté collégiale}

Dans la structure officielle de l'appareil institutionnel, dans l'ordre du discours structuré par les pouvoirs publics, dans la construction du mythe de la royauté et dans le rituel qui alimentait l'imaginaire collectif, le roi occupait évidemment, indiscutablement, la première place. Il était le chef suprême de l'État, le représentant direct de Dieu dans le royaume. Cette structure était indispensable, à plusieurs niveaux et pour plusieurs raisons, à la légitimation et au fonctionnement de l'État absolu. En premier lieu elle servait pour assurer une substantielle protection autour de l'action des fonctionnaires publics (aussi des ministres et des autres titulaires d'une fonction administrative que des hauts magistrats et des autres juges du royaume, ainsi que de tous ceux qui étaient titulaires de fonctions de judicature).

Grâce à la primauté absolue du souverain et à son investiture par le droit divin, ils restaient tous à l'abri de toute responsabilité, car ils agissaient par délégation du roi et ce dernier ne répondait quà Dieu de ses actions. Tant qu'un officier ne contrevenait manifestement pas à un ordre du roi ou à une loi en vigueur - dans ce cas là on l'aurait accusé de " forfaiture », " haute trahison » ou " lèse-majesté » - il pouvait être tranquille : ni le roi, ni personne, n’aurait pu l'atteindre dans l'exercice de ses droits. Il était de fait inamovible.65 Sa charge étant de sa propriété, on aurait considéré que le roi commettait une violation gravissime de l'un de ses devoirs les plus importants s'il avait entrepris de chasser de son office un officier qui n’aurait pas été préalablement condamné au terme d'un procès régulier. 66

64 Recueil de Traittés [sic] de droit public. Différentes matières; t. V, fo 34 (= Bibliothèque du Sénat, $m s$. n. 21 [8932]) ; les fos 5-70 de ce volume sont consacrés entièrement au « Grand Conseil ». Cf. Di Donato (2003a : 681-684).

65 Cf. Antoine 1994.

66 C'était là justement la motivation de l'agitation parlementaire au moment du célèbre épisode du magistrat Carré de Montgeron que Louis XV fit arrêter et emprisonner à la Bastille sans 
C'est exactement cet argument, très fort et très présent dans le royaume, que les robins (appuyés en cela par beaucoup de monde, y compris des philosophes et hommes des Lumières qui, c'est le moins que lon puisse dire, nétaient pas vraiment parmi leurs amis les plus fidèles) brandirent contre le roi et le gouvernement à l'époque de la réforme du chancelier Maupeou en 1771 et à laquelle ils donnèrent le nom de " coup d'État ». Leur propagande efficace se fondait justement sur l'idée que le roi était voulu par Dieu pour protéger la liberté et la propriété des sujets. Le berger - on se servait alors de cette métaphore biblique - doit gouverner le troupeau, il ne peut ni lécharper ni le dévorer.

Toute la structure des offices publics bénéficiait de cette forme d'immunité substantielle. Les ministres qui composaient les conseils privés, ${ }^{67}$ avant tout le reste de l'appareil de l'État, en tant quémanation immédiate du roi, non seulement jouissaient d'une position de grand prestige, mais en même temps exerçaient le pouvoir gouvernemental par délégation du souverain dans une condition d'immunité politique presque totale, sauf le risque dêtre limogés par le roi lui-même. Il n'y avait en effet que le roi qui pouvait décider de les supprimer. Le Parlement et les autres cours, qui se qualifiaient elles-mêmes de "souveraines ", venaient, dans cette hiérarchie institutionnelle, juste après, dans une position un peu plus décalée. Elles étaient considérées, certes, comme des institutions tout de même de très haut niveau, mais en tout cas le roi les tenait bien clairement en-dessous des conseils privés et aussi du Grand Conseil. ${ }^{68} \mathrm{Si}$ l'on suit la doctrine des publicistes du XVIème siècle, le roi était perçu et célébré comme l'image vivante du pouvoir de Dieu sur terre et il était le pivot de tout l'appareil de l'État. 69

Toutefois, si l'observateur d'aujourd'hui, extérieur à ce monde qui lui apparaît si différent du sien, a la patience d’aller au-delà des apparences, il ne tardera point à s'apercevoir que l'image publique de la monarchie, dont le cérémonial se fondait sur la primauté absolue de la figure du roi, ne correspondait pas tout à

procès, après avoir reçu directement des mains de ce téméraire robin le soir du 29 juillet 1737 dans le parc de Versailles le 'don' du fameux livre contenant la description de plusieurs miracles advenus sur le tombeau du diacre François Pâris, emblème de l'opposition jansénisante du Parlement au gouvernement royal. Le récit détaillé de lépisode et de ses suites politicoinstitutionnelles est dans des manuscrits conservés à la Bibliothèque du Sénat, au Palais du Luxembourg, fonds Boissy d'Anglas 799 [9260] : « Extrait des choses les plus importantes qui se sont passées au Parlement - 1719-1746», par Guy Nouet, fos. 246r-v. et suiv. Sur cet argument, cf. Di Donato (2003a : 91-92).

67 Cf. Mousnier 1947 et 1970b ; Antoine 1951, 1970, 1973 et 1975.

68 Tel est aussi le schéma suivi sans hésitation par toute l'historiographie moderne des institutions, qui traite dans un rigoureux ordre hiérarchique Cf. Mousnier 1947, 1970b ; Antoine 1951, 1970, 1973, 1975 ; Hamscher 1987, 1989 ; Harouel et alii (1987 : 4h15-553); Barbiche (1999 : 117-311 et 335-358); Saint-Bonnet-Sassier (2004: 200-227).

69 Un exemple parmi les nombreuses sources disponibles : Bignon 1610. Pour des interprétations historiographiques suggestives, cf. Marin 1981; Boureau 2000 ; Mousnier (2002, spécialement 43-72, 110-181, en particulier 172-174: « Le roi absolu comme image vivante du pouvoir $»$ ). 
fait - et parfois pas du tout - à la dure réalité des relations politiques et institutionnelles. Le « métier de roi » était bien plus « dur » que le mythe de la royauté ne le laissait entendre. ${ }^{70}$

On ne saurait compromettre ce schéma qui convenait particulièrement aux officiers, car il s'agissait d'un excellent instrument non seulement pour préserver leur responsabilité, mais aussi pour construire la centralité politique de l'appareil judiciaire, en profitant de la protection déterminée par l'image suprême de la royauté. En effet, les « légistes » (comme on les appelait au Moyen Âge), bientôt « hommes de robe ", visaient à construire un pouvoir occulte qui, sous l'exaltation purement formelle du principe de l'" unicité de la souveraineté », comme l'a écrit Jacques Krynen utilisant une formule qui décrit synthétiquement et parfaitement la réalité effective, donnait lieu à une " royauté collégiale ».71

Le corps des juristes avait donc un intérêt formel à maintenir intacte, voire à intensifier, dans l'imaginaire collectif, cette idée de la puissance " absolue " du roi. En même temps, ils avaient, à l'opposé, un intérêt réel - et plus profond - à dégarnir le plus possible les pouvoirs du souverain pour les transférer dans - pour reprendre la belle expression utilisée dans un important traité au tout début du XVIIIème siècle - « les prérogatives de la robe ».72

Si l'on comprend le fonctionnement subtil de cette structure théorico-pratique sur laquelle le corps des juristes, et les institutions où ils opéraient en position d'hégémonie, édifiaient leur capacité d'influencer le cours des affaires publiques, tous les discours ainsi que les actions politiques du corps judiciaire - et plus généralement des " hommes de droit »- prennent sens et cohérence. On évite ainsi d'accorder le moindre crédit aux apparentes contradictions dans lesquelles on pourrait s'empêtrer (comme celle selon laquelle les hommes de robe sont des monarchistes avérés, des défenseurs acharnés du système sociopolitique de l'État absolu, ${ }^{73}$ mais en même temps ils n'agissent qu'en vue d'empêcher au roi de gouverner et parfois la violence de leur action arrive à donner

70 Cf. Antoine 1986.

71 Cf. Krynen 1993 ; Saint-Bonnet-Sassier (2004 : 208).

72 Cf. Bértaut de Fréauville 1701.

73 Parfois l'historiographie est tombée dans le piège du discours de robe et s'est limitée à souligner seulement l'aspect de la fidélité des juristes au pouvoir absolu sans le contrebalancer avec l'analyse de la pensée constitutionnelle élaborée par les milieux parlementaires et par l'examen des événements (la dure action des magistratures en opposition du pouvoir gouvernemental). Ainsi quelques historiens ont cru naïvement aux formules absolutistes des robins, en les prenant pour vraies sans réserve, tandis qu'il est évident que ses formules composent, au contraire, le raffiné et cynique réseau conceptuel d'un discours purement formel. Et en suivant cette erreur certains ont du dévaluer toute l'opposition des cours souveraines au gouvernement royal - notamment au XVIIIème siècle - et considérer la querelle magistrature-couronne comme un discours faux. L'exemple le plus évident de cette interprétation excentrique du phénomène en question est le livre de Maire 1998. 
l'impression qu'ils souhaitent même une suppression du souverain, comme le démontre, entre autres, l'affaire Damiens en 1757). ${ }^{74}$

\subsection{La hiérarchie des valeurs normatives dans les négociations politiques secrètes}

L'instrument institutionnel que la magistrature utilisait pour convertir la juridiction parlementaire en participation politique à l'exercice de la souveraineté était le jugement constitutionnel. Cet acte de juridiction se réalisait à travers une structure procédurale complexe dans laquelle le Parlement faisait rentrer trois formes principales de "vérification " : 1. le contrôle de légalité : on soumettait la loi du roi à une analyse fondée sur son éventuel conflit avec les lois fondamentales ou avec des principes de droit divin ou naturel ; 2 . le contrôle d'opportunité : on vérifiait lexistence des conditions externes (entendues lato sensu, donc politiques, sociales, économiques, culturelles, religieuses...) qui pouvaient favoriser ou au contraire gêner l'application correcte de la loi ; 3. le contrôle d'équité : on examinait un texte du point de vue de ses éventuelles contradictions internes et des fautes de logique qu'il pouvait contenir.

Naturellement cela était l'effet de multiples négociations souvent très dures qui se faisaient en secret, dans les cabinets des ministres à Versailles où les présidents des chambres parlementaires (spécialement des enquêtes) se rendaient le soir pour traiter en présence du chancelier et (plus rarement du roi lui-même) de plusieurs affaires directement avec eux. On ne saurait trouver nulle part dans les sources officielles les traces de ces procédures secrètes. Néanmoins elles existaient, mieux, elles nétaient pas du tout exceptionnelles. Cétait la normalité dans la vie politique et institutionnelle de l'État « absolu».

Ces « conférences » versaillaises étaient régulièrement le vrai creuset de la législation. Les normes législatives de l'Ancien Régime étaient de fait le résultat ultime de pourparlers préventifs et souterrains, qui se déroulaient bien avant que le texte ne soit présenté au Parlement pour l'enregistrement et, à plus forte raison, bien avant que la loi ne soit promulguée comme acte unilatéral du souverain absolu. ${ }^{75} \mathrm{La}$ formule «car tel est notre plaisir » nétait que le sceau apposé à une préalable et très complexe procédure formelle et (surtout) informelle dans

74 Cf. Van Kley 1984. Pour la thèse de l'implication des robins dans l'attentat de Louis XV, prouvée par des documents qui paraissent à mes yeux très clairs et sans malentendus possibles, cf. Di Donato (2003a : 372-379).

75 Une étude spécifique et mise à jour, après celle réalisée par Petit-Renaud 2001 pour le Moyen Âge (argument sur lequel cf. le magistral recueil de Rigaudière (2003 : IIème partie, 175-341) ; il manque encore, dans la littérature historiographique, des études sur ce même argument lors des siècles de l'Ancien Régime et il serait fort souhaitable qu'elle soit commencée. Beaucoup de document utiles à cet égard se trouvent à la Bibliothèque (Annexes des Archives) du Sénat français, au Palais du Luxembourg, spécialement (mais pas uniquement) dans le fonds Boissy d'Anglas. 
laquelle la phase de la négociation et de recherche d'un accord constituait la partie la plus importante. On peut bien dire, en empruntant pour cette perspective les mots que Spinoza avait utilisés pour le concept de "nature ", qu'au delà de sa vitrine, l'absolutisme était réellement un système politique d'une « somptueuse complexité ».76

L'historien qui ne se contente guère du dépouillement des sources officielles, s'amuse à relever comment le projet de loi que le roi et son gouvernement avaient présenté au Parlement pour obtenir l'enregistrement, se modifiait dans plusieurs cas au cours de la procédure et fléchissait dans un texte qui était visiblement le résultat du compromis obtenu par les deux délégations. Parfois ce compromis pouvait concerner aussi plusieurs lois. Si le Parlement cédait sur l'une il pouvait gagner sur l'autre. Et le gouvernement de même.

Il est très clair alors que dans ces négociations chaque partie mettait en place (elle était même contrainte de le faire) une hiérarchie de valeurs. Cette hiérarchie était de fait imposée par la structure même des relations entre gouvernement et magistrature. Si lon voulait maximiser les possibilités de succès, il fallait savoir préalablement à quoi on pouvait renoncer ou non. Dans la plupart des cas on arrivait à trouver un compromis. Lorsqu'on n'y arrivait pas, car les deux parties considéraient telle disposition de la loi comme un point auquel on ne pouvait pas renoncer, éclatait une crise politique et avec elle, bien souvent, une crise constitutionnelle..$^{77}$ Cela arriva par exemple en 1730-31, en 1753 au prétexte de l'affaire du refus des sacrements, en 1756, en 1766 à propos de l'affaire La Chalotais et, bien évidemment, en 1771 avec la réforme Maupeou.

Il va de soi que les trois formes de contrôle pouvaient aussi être cumulées. Le Parlement acquérait en ce cas un pouvoir très étendu, car il réussissait à pénétrer en profondeur dans le contenu de la loi et souvent à contraindre le gouvernement et le roi à modifier certaines dispositions ou à les formuler en un texte quand même différent. C'est surtout à travers la deuxième vérification (le contrôle d'opportunité qui appréciait les conditions « externes ») que la magistrature arrivait à jouir d'un immense pouvoir de contrôle. Les instruments, très raffinés, de la rhétorique robine, fruit de l'expérience séculaire que lordre du discours juridique avait construit, pouvaient réaliser tout résultat par assimilation ou par disjonction conceptuelles.

Les juristes maniaient la logique comme personne et savaient s'en servir pour démontrer leurs arguments avec une rigueur conceptuelle désarmante. Ainsi ils

76 Je renvoie sur ce concept à mon essai: Di Donato (2002: $\$ 15, \mathrm{CXV}-\mathrm{CXXVI}$ ).

77 Le recours au lit de justice se rendait nécessaire dans des circonstances extraordinaires. Malgré la possibilité formelle d'utiliser ce puissant instrument de l'autorité royale les rois n’y parvenaient que mal volontiers car ils connaissaient très bien les conséquences que ce choix aurait impliquées dans les relations déjà tendues avec la magistrature. Voir sur l'argument, Hanley 1991 et Brown-Famiglietti 1994. 
navaient guère de difficultés à procéder dans un raisonnement qui pouvait faire apparaître les contradictions d'une loi avec elle-même ou avec d'autres conditions externes là où il n'y en avaient pas. L'interprétation savante et sapientiale des $s a-$ cerdotes juris était, donc, un instrument de pouvoir formidable et inattaquable. Tout discours sur la souveraineté dans l'État absolu devrait prendre en compte cette réalité qui paraît évidente à tous les habitués des archives judiciaires. ${ }^{78}$

Les juristes les plus notoires, qui devinrent des idola fori, des personnages presque mythifiés dans l'histoire de la robe, ne manquèrent pas de courage pour dire ouvertement au roi que la vérification parlementaire nétait pas du tout un acte purement formel, mais au contraire quelle impliquait un véritable contrôle judiciaire sur la législation. Exemplaire à cet égard le « rappel » fait par le président de Harlay à Henri IV en 1605 : "Les édits - dit-il - sont envoyés au Parlement non seulement pour procéder à la vérification mais pour en délibérer selon les règles ordinaires de la Justice $» .79$

\subsection{Le paradoxe suprême : une hiérarchie entre normes de rang équivalent}

L'existence d'un contrôle de constitutionnalité dans l'ordre juridique de l'Ancien Régime, contrôle dont il ne faudrait pas exagérer la portée, ${ }^{80}$ est désormais reconnue par plusieurs spécialistes. ${ }^{81}$ L'inexistence d'un texte constitutionnel rédigé selon le style auquel nous sommes habitués aujourd'hui, c'est-à-dire le style inauguré par la « codification constitutionnelle » de la Révolution, nétait nullement un obstacle à ce type de jugement sur les lois du roi.

Comme on l'a vu, les parlements considéraient que la constitution du royaume était gravée dans les lois fondamentales, dans le droit divin et naturel et dans la Tradition juridique du royaume dont l'interprétation était réservée aux cours souveraines, c'est-à-dire en premier lieu à eux-mêmes, les seuls qui avaient droit d’atteindre au dépôt légal. Les délibérations de ces organes juridictionnels (sous n'importe quelle forme : arrêts, remontrances, arrêts de règlement) 82 formaient à leur tour l'ensemble des principes appliqués qui constituaient pour les robins le noyau du droit français. ${ }^{83}$

78 Parmi les nombreux ouvrages qui sont dernièrement parus sur l'argument de la souveraineté, je me limite à signaler ici Cazzaniga-Zarka 2001 et Quaglioni 2004.

79 Richet (1973: 33).

80 Cf. Léca 1987.

81 Cf. Mestre 1992 ; Gojosso 1999, 2001 et 2002 ; Saint-Bonnet 2001. Récemment moi-même j’ai publié sur ce sujet un essai spécifique, en deux parties, auquel je renvoie : Di Donato 2004 et 2005 (voir la bibliographie citée ibidem).

82 Cf. Payen 1997 et 1999.

83 Cf. Di Donato (2003a : spécialement 466-470) (chap. III, $\$ 13$ : « Le contrôle de constitutionnalité : un instrument juridique de contrôle politique »). 
On peut donc bien observer dans la "pratique du système » 84 que cétait laction de la haute magistrature qui faisait vivre et déterminait la hiérarchie entre des différentes sources normatives à travers son contrôle exercé sur les actes législatifs du souverain et de ses Conseils privés. Il va de soi que la possibilité d'un contrôle de constitutionnalité présupposait une hiérarchie des normes et par conséquent l'existence d'une constitution en vigueur dans l'État absolu. ${ }^{85}$

Tout cela nous porte à conclure que le contrôle de constitutionnalité effectué par les parlements de l'Ancien Régime nétait pas uniquement centré sur le droit formel ; il présupposait une forme particulière de hiérarchie normative: une hiérarchie qui pouvait se déterminer tantôt entre sources de différents niveaux, tantôt entre sources normatives de rang formel équivalent. Ce concept est difficile à cerner dans un contexte juspositiviste - comme celui de la plupart des ordres juridiques d’aujourd'hui - où la hiérarchie normative présuppose nécessairement l'existence de sources de différents niveaux formels, comme, par exemple, la constitution et la loi " ordinaire».

Souvent les robins, s'ils ne voulaient pas d'une loi présentée par le souverain au Parlement pour l'enregistrement, argumentaient que cet acte-là était en conflit avec d'autres lois déjà en vigueur, produites par les monarques précédents. En effet, sur un plan purement formel, il nétait point illégitime qu'un roi puisse abroger ou modifier un acte législatif d'un de ses prédécesseurs (la maxime tiré du droit romain : "lex posterior derogat priori », fût considérée comme toujours en vigueur et comme un critère efficace pour résoudre les antinomies), en pratique, en revanche, cela était fort déconseillé aux souverains.

Voilà un cas éclatant de contrainte juridique qui opérait dans l'effectivité des relations politiques. Un roi, étant investi de la divine potestas, ne pouvait pas être démenti avec tant d'éclat par l'un de ses successeurs sans que l'entier système ne reçoive un coup très violent et par conséquent très dangereux pour la stabilité socio-institutionnelle. Lordre juridique et politique se légitimait par la croyance populaire et se fondait sur la confiance que le roi incarnait la Justice divine et qu'il ne pouvait pas se tromper quand il agissait comme représentant direct de Dieu.

Or, la législation était non seulement l'aspect révélateur de la souveraineté, mais surtout elle était sur le plan symbolique le pouvoir fondamental du roi, car dans la forma mentis de l'homme de l'Ancien Régime, Dieu seul est Législateur et le roi a reçu de Dieu la délégation directe (à travers le sacre et l'onction) de légiférer en son nom. "Faire loi » était en somme - dès le Moyen Âge - 86 la prérogative suprême dans le cadre de l'ordo juris fondé sur le droit divin. Par consé-

84 L'expression sort de la plume de Richet (1973: 65 et s.).

85 Sur le concept de « constitution » dans l'État absolu, cf. Mousnier (2002, passim, et spécialement 110-129).

86 Cf. Petit-Renaud 2001. 
quent cette prérogative devait nécessairement être liée à l'idée de " Justice ». Le roi est absolu "pour faire régner la justice ».87 Un roi qui crée des normes injustes est inconcevable dans ce contexte là.

Cette idée constituait le présupposé de la stabilité politique, institutionnelle et sociale. Mais avant tout il s'agissait d'une valeur culturelle que la mentalité des juristes avait absorbé ab imis fundamentis. De cette perpétuité ils se considéraient les plus jaloux et rigoureux interprètes. Si aucun roi ne peut créer des choses ouvertement injustes, on ne peut non plus contredire frontalement cette volonté par l'expression d'une volonté législative opposée. Cette idée était nourrie par une vision théorique de fond qui innervait toute la mentalité sociale et politique de l'Ancien Régime. D’après la spéculation de Thomas d'Aquin, on en avait tiré une valeur éminemment aristotélicienne :

Ces considérations montrent avec évidence - avait écrit le philosophe de Stagire dans sa Politique - que des changements sont opportuns sont certaines lois et dans certains cas. Mais /.../ une grande circonspection paraitre s'imposer dans ce domaine. Quand, en effet, l'avantage quon retire du changement apporté est de faible intérêt, et comme, en revanche, il est dangereux d'habituer les hommes à abroger les lois à la légères, mieux vaut manifestement fermer les yeux sur quelques erreurs des législateurs ou des magistrats, car le profit qu'on pourra retirer d'une modification de la loi sera loin de compenser le dommage qui sera causé par l'habitude de désobéir à ceux qui gouvernent. /.../ La loi na aucun pouvoir de contraindre à lobéissance en dehors de la force de la coutume, et celle-ci ne sétablit quaprès un laps de temps considérable, de sorte que passer facilement des lois existantes à de nouvelles lois toutes différentes, c'est affaiblir lautorité de la loi. 88

Le roi-législateur, tout en étant "souverain dans son royaume ", ne peut donc créer des normes juridiques complètement à son gré. Il doit respecter tout un ensemble de bornes. La législation royale nétait donc pas du tout aussi absolument libre que ne le faisait croire la propagande absolutiste (et pourtant nécessaire) que les juristes, eux-mêmes, par convenance stratégique, contribuaient à alimenter.

Le pouvoir de produire des nouvelles normes juridiques était, au contraire, inséré dans une sphère prédéterminée de principes qui lorientaient et le légitimaient en même temps. Ces principes nétaient pas abstraits ; ils étaient plongés au fur et à mesure dans un contexte déterminé, par le biais de l'interprétation qui était aussi le fruit des «lumières » de la Scientia Juris. Les juges appliquaient les principes fondamentaux aux cas particuliers concrets et en tiraient des " maximes » qui éclaircissaient les mêmes principes juridiques. C’était un processus circulaire.

87 Je renvoie sur ce point à mon essai : Di Donato (2002 : CXXIV).

88 Aristote, La Politique, livre II, $\$$ 8, 1269a (« Examen de la constitution d'Hippodamos de Milet »). Sur l'influence de l'aristotélisme sur la pensée juridique, cf. Villey (2003 : 78-99, 149-176 et passim). 


\subsection{La juridiction comme fondement ultime de la supralégalité constitutionnelle}

C'est à cause de cela que plusieurs auteurs entre le XVIème et le XVIIIème siècles se sont montrés très soucieux de souligner et de démontrer que l'ordre juridique de la France monarchique-absolue était « complexe », ce qui signifiait en effet qu'il était fondé sur plusieurs sources et pas uniquement sur la loi du roi. L'un des témoignages parmi les plus clairs à cet égard est celui d'Étienne Pasquier, selon lequel le

droit commun de la France gist en quatre points; aux ordonnances royaux, coustumes diverses des provinces, arrests généraux des cours souveraines, et en certaines propositions morales, que par long et ancien usage nous en tenons en foy et hommage du Romain. 89

Il faut souligner, dans ce passage si important et pour lévolution du droit français moderne et pour son profond rapport avec le développement de l'État de droit, la place de source normative véritable accordée à la jurisprudence des cours de justice souveraines. Ces dernières se voyaient reconnaitre la tâche (et par conséquent un véritable droit/pouvoir) de raccorder la législation royale avec les grands principes (expressément laissés dans un nombre et un contenu vagues) qui formaient le noyau dur du droit public constitutif, voire le droit constitutionnel, de l'État.

Cela confirme non seulement qu'il y avait un système structuré de sources du droit et que ce système était ordonné sur plusieurs niveaux hiérarchiquement disposés, mais aussi que toute cette hiérarchie tenait debout par création jurisprudentielle. C'est grâce à la jurisdictio des cours de justice, et notamment à la savante et sapientiale médiation des parlements, que la hiérarchie des normes se constituait et vivait.

La jurisprudence "souveraine " s'autoconstituait ainsi comme une véritable supralégalité constitutionnelle, car c’était elle qui établissait la légitimité d'une loi du roi sur la base de principes dont elle même se considérait dépositaire. Cette structure du droit enraciné dans l'activité jurisprudentielle était conçue par les juristes-magistrats comme l'instrument fondamental qui assurait le bicéphalisme du système politico-institutionnel. ${ }^{90}$ Elle était donc destinée à coexister avec la construction du mythe de l'État absolu. ${ }^{91}$

C'est là le point le plus délicat de tout le système juridique et politico-institutionnel de la société d'Ancien Régime. Tout tenait autour de ce paradoxe que les principaux juristes tâchaient de résoudre ou tout de même d’atténuer : il fallait

89 Pasquier 1560-1567. Cf. Richet (1973:29).

90 Le bicéphalisme du système politico-institutionnel français fut bien noté par Mme d'Épinay, cf. infra note 160 .

91 Pour la construction théorique du «mythe de l'État », les pages classiques de Cassirer 1993 restent suggestives. 
sauvegarder l'abstraite liberté législative du souverain (en l'absence de laquelle on naurait plus eu un système absolutiste, mais républicain, ce que les juristes craignaient comme le feu craint l'eau) sans toutefois ébrécher l'auctoritas de la Traditio centrée sur le concept de " constitution du royaume ", ce qui permettait aux jurisconsultes, à travers la savante manipulation interprétative, de sattribuer la réelle - quoique occulte - puissance de légiférer.

Pour obtenir ce résultat il fallait revêtir le pouvoir législatif que la jurisdictio parlementaire revendiquait des apparences du contrôle des actes normatifs produits par le roi. La magistrature niait vouloir (et même pouvoir) posséder une portion du pouvoir législatif. Par la bouche de Montesquieu elle parvint à déclarer que le pouvoir judiciaire nétait qu'une " puissance nulle ».92

Sur le plan formel « faire loi » était une prérogative exclusive du seul roi. Mais, en même temps, le souverain nétant pas un despote, il devait respecter dans sa législation « certains principes » - ces " propositions » dont parlait Pasquier qui composaient la " constitution du royaume ", il fallait alors soumettre les actes normatifs que le souverain lui-même produisait à une vérification qui pouvait établir s'ils étaient compatibles avec ce « corps monumental» de valeurs et de «maximes » explicitant la Tradition constitutionnelle du royaume.

\subsection{La loi prisonnière de la loi}

La législation devait, en somme, être inspirée par le double critère du respect des normes de niveau supérieur et de la cohérence nomothétique. Elle ne pouvait pas facilement - ni, en tout cas, ouvertement - dévier de la voie, du lirium, tracée par la Providence divine.

La déviation au-delà de cette recta via aurait été considérée justement dans cette optique comme un de-lirium, ${ }^{93}$ comme un saut dans le vide, bref comme une folie. Il y avait - par admission explicite de plusieurs rois eux-mêmes " une contrainte rendant les souverains prisonniers de leur propre législation $» .94 \mathrm{Il}$ fallait, donc, inventer une formule qui permît de concilier l'envers et l'endroit de la médaille. Pour la stratégie des juristes il était indispensable de faire coexister la monarchie absolue et le constitutionnalisme juridictionnel qui trouvait son rempart dans le Parlement. 95

92 Cf. Cayla-Renoux-Zagamé 2001.

93 Sur ce concept voir Bodei 2000.

94 Richet (1973: 28). Tout le monde pensait à l'époque que « le roi de France, à la différence d'un Sultan de Turquie, doit respecter sa propre loi ». Henry IV et Louis XIV, pour ne citer que deux exemples parmi les plus significatifs, reconnurent ce principe de fond. Le premier affirma péremptoirement : «La première loi du souverain est de les observer toutes »; le second (quoique plus vague) aussi : "La parfaite félicité d’un royaume est qu’un prince soit obéi de ses sujets et que le prince obéisse à la loi ».

95 Je crois avoir démontré cette interprétation historiographique par plusieurs textes, surtout du XVIII siècle, publiés dans mon étude monographique: Di Donato 2003a. 
Si la juridiction devait être le complément nécessaire de la loi, au sens où la loi nexistait que par le biais de son interprétation-application, il fallait par cohérence logique affirmer que la loi elle-même ne pouvait pas violer d'autres lois déjà interprétées par la jurisprudence. Le Parlement affirmait que son action interprétative était véritablement partie prenante du processus législatif permanent et que cette activité était au service du roi. La magistrature était le rempart de la législation royale et cétait grâce à elle que les rois pouvaient légiférer de façon cohérente et non pas de façon anarchique et capricieuse. Comme le roi " ne mourrait jamais » 96 - car il y avait une ligne de continuité dans la succession - cette limite posée à l'activité législative ne pouvait uniquement concerner la personne physique de tel ou tel roi, mais elle concernait «le roi » en tant qu'institution principale du royaume. Par conséquent, dans la doctrine parlementaire, la personne singulière d'un roi pouvait changer très peu de choses à la législation consolidée laquelle faisait désormais partie de lordre juridique du royaume, de sa «Tradition".

Ce problème était d'ailleurs bien connu des jurisconsultes et des théoriciens du droit dès les XVème - XVIème siècles. Parfaitement conscient de cette difficulté intrinsèque au système, Jean Bodin, dont la culture d' « humaniste possédant des connaissances encyclopédiques ${ }^{97}$ peut être considérée à juste titre comme un extraordinaire croisement de traditions juridiques et de cultures politiques, avait créé la formule devenue célèbre de la confirmation "par souffrance » qui était en effet une litote conceptuelle: au lieu d'affirmer qu'un roi pouvait donner la forme de loi à tout ce qu'il voulait, sans tenir compte du fait que les nouvelles normes pouvaient être en conflit avec des normes précédentes, il soutint que tout le droit précédent restait en vigueur "par souffrance ", c'est-à-dire par consentement tacite, du nouveau roi.98 Tant que ce dernier n'intervenait pas avec une volonté abrogative explicite, en déclarant supprimées les normes déjà existantes, elles continuaient dêtre en vigueur.

Cette ruse conceptuelle était fort opportune car elle servait à éviter que le royaume ne tombe dans l'" anarchie » et l'" arbitraire». L'" artifice» juridique était conçu en vue d'empêcher qu' " un héritier léger, ou rieur ", ou plus simplement un nouveau roi avec un esprit « réformateur » puisse, en montant sur le trône, annuler " le travail législatif de ses prédécesseurs ".99 Par conséquent s'il voulait casser une loi, le roi était obligé de manifester une volonté claire et directe d'abroger chaque norme qu'il jugeait incompatible avec son projet de gouvernement.

\footnotetext{
96 Cf. Giesey 1987a.

97 Cf. Richet (1973: 45).

98 Cf. Richet (1973:29).

99 Cf. Richet (1973:28).
} 
Mais cette volonté abrogative était rarement formulée en des termes si explicites. Le roi n'avait aucun intérêt à apparaitre en destructeur de l'ordre juridique consolidé. Au contraire l'image qu'il tenait à diffuser de lui-même était celle du bon père, doux, tempérant, sage ; et aussi celle, biblique, du berger qui fait paître le troupeau des moutons et le protège de l'agression des loups. Dans les deux cas, le concept de fond qu'il aimait (et devait) transmettre à ses sujets était le même : " Je suis celui qui est appelé par la volonté de Dieu à conserver le royaume dans ses traditions ». Comme la " fidélité » était " la sève vitale du corps politique », chaque sujet était " fidèle " à quelqu'un d'autre; le roi était tenu dêtre "fidèle au royaume ». 100 Contrairement à notre habitus mental contemporain, le changement assumait une valeur négative dans la mentalité de l'homme de l'Ancien Régime, tandis que les concepts de stabilité et de répétition étaient considérés hautement positifs. ${ }^{101}$

C’est pour cela que l'abrogation ne figurait pas à plein titre au nombre des concepts juridiques fondamentaux. Les juristes ne lui accordaient pas une place importante ni dans leur formation ni dans l'activité pratique. Dans le milieu juridique - et dans les Écoles de droit - on préférait plutôt utiliser le concept de «désuétude » des lois. Et l'on comprend aisément pourquoi. Une loi désuète nétait pas, pour autant, comme la loi abrogée, une loi complètement éliminée du corpus des lois du royaume. Sur le plan formel elle restait toujours dans l'ordre juridique. Cela voulait dire en pratique quelle était prête à être réappliquée le cas échéant, lorsqu'un organe judiciaire trouvait convenable de recourir à cet escamotage pour sortir d'une difficulté processuelle. La désuétude était, pour ainsi dire, la retraite de la norme, tandis que l'abrogation était sa disparition définitive. La constatation de la désuétude d'une norme était, à l'instar de l'application d'une loi, une affaire réservée à l'appréciation d'une cour de justice. Cette évaluation étant éminemment technique, la magistrature pouvait l'exercer en totale liberté. C'était un pouvoir totalement discrétionnaire. Et, à bien y regarder, cétait en cela une entité très liée à la hiérarchie des normes. Une loi désuète pouvait en effet rentrer à l'improviste dans le jeu, comme un coup de théâtre, bouleversant ainsi la hiérarchie traditionnelle et exerçant un poids dans un jugement (qui pouvait être aussi un jugement de constitutionnalité porté sur une autre loi). Comme il pouvait y avoir différents degrés de désuétude, il était très facile, même pour un interprète à peine avisé, de faire valoir un argument en faveur de la reviviscence d'une ou plusieurs normes (partiellement) désuètes. En somme : l'abrogation soustrayait son pouvoir à l'activité d'interprétation, tandis que la désuétude l'augmentait.

100 Cf. Mousnier (2002: 58-60).

101 Mousnier (2002: passim, spécialement dans le cadre des chapitres IV de la Ière partie; I, II et III de la IIème partie ; I de la IIIème partie). 
C'est la raison pour laquelle un ouvrage comme le Legum abrogatarum et inusitatarum tractatus de Philibert Bugnyon, publié pour la première fois en 1563, fut regardé à son début avec méfiance de la part du corps juridique et jugé par les juristes-magistrats comme étant généralement dangereux pour l'équilibre politico-institutionnel établi dans l'État absolu. ${ }^{102}$ Ce nest pas par hasard que son auteur paya son insolente inventivité par une carrière médiocre et sa marginalisation. On ne pouvait lui pardonner la hardiesse d'avoir présenté, dans un cadre ordonné et systématique, toutes les « lois abrogées » et surtout celles qui étaient tombées en désuétude, c'est-à-dire celles que l’on voulait faire oublier sans recourir à la procédure claire et nette de l'abrogation. Ainsi il ne parvint jamais à rentrer dans une magistrature de rang supérieur et ne put non plus assumer un office d'une certaine importance. Tout ce qu'il obtint - consolation bien maigre pour un homme aussi talentueux que lui - fut une simple fonction $d^{\prime}$ ' avocat du roi » dans une modeste et inoffensive élection de province. 103

Cet exemple nous suggère une réflexion sur la résistance du milieu de robe à mettre en évidence l'abrogation des lois. Le mécanisme privilégié pour se défaire d'une loi était plutôt celui de la laisser tomber aux oubliettes. Tout simplement les cours de justice ne l'appliquaient plus ou ne relevaient pas son inapplication par d'autres organes de l'État ou par les sujets. Cette pratique judiciaire visait à favoriser la diffusion de l'idée que l'ordre juridique était parfait et qu'il n'y avait pas de changements et à plus forte raison de bouleversements à faire. En matière de droit, lontologisme - voire la stabilité providentielle du système juridique et institutionnel - devait régner en maître.

Gardiens de cette volonté de conservation, les magistrats, notamment ceux des parlements, se sentaient investis de la tâche de veiller sur les comportements du roi et de contrôler l'effectivité de ses propos, qui avaient été assumés avec le serment prêté pendant la cérémonie du sacre.104 Ils utilisaient l'enregistrement parlementaire - qu'ils considéraient bien évidemment comme «la plus essentielle des lois fondamentales »- comme l'instrument juridictionnel de ce contrôle politique sur la couronne et sur l'activité législative de son gouvernement. Ils s'appuyaient, comme on l'a remarqué plus haut, sur l'idée aristotéli-

102 Cf. Bugnyon 1702. Ce Traité eut quatre éditions (trois en français et une en latin) entre 1563 et 1578 et fut actualisé à plusieurs reprises (entre autres par un célèbre juriste comme Pierre Guésnois ; cette édition fut publiée chez Veuve G. Chaudière, Paris 1602). La dernière et plus complète édition fut celle « apud Petrum de Dobbeleer, Bruxellis 1702 ».

$103 \mathrm{Ph}$. Bugnyon a vécu entre 1530 et 1590 : docteur ès droit à Avignon, avocat en la sénéchaussée siège présidial de Lyon et Parlement de Dombes, il fut reçu ensuite comme conseiller du roi et son avocat en l'élection de Lyon et pays maconnais. La fortune du Traité fut décidément posthume et certainement elle ne regarda guère la haute magistrature. Je renvoie sur cet argument intéressant concernant le faible intérêt porté sur les lois abrogées et inusitées par le corps parlementaire, à un travail de recherche que j'ai en cours et qui sera prochainement publié.

104 Cf. Giesey 1961, 1987b, 2004. 
cienne selon laquelle, en général, le changement législatif était un mal en soi, indépendamment de la qualité des contenus normatifs. 105

La stabilité était une valeur absolue, car elle était une conséquence directe de la structure ontologique de l'État, qui était considérée immédiatement comme descendant du Verbum et de la Veritas. Ces valeurs étaient absolues, uniques et parfaites. Elles nétaient point susceptibles d'amélioration. Dans une organisation sociale comme celle de l'Ancien Régime, qui était fondée sur l'idée de continuitas, c'est-à-dire sur la dérivation ab aterno et sur la perpétuation per aeternum de mœurs et de pratiques considérés comme universels, 106 le changement aurait comporté en soi-même un bouleversement stupéfiant dans les esprits. Si ce changement avait concerné les aspects constitutifs, voire les fondement du système, ce que les juristes appelaient « mutations constitutionnelles » ou selon le lexique aristotélicien l'" essentia rerum », il aurait porté inévitablement un "vulnus ", une blessure inguérissable au corps social et à l'ordre juridique et politique, avec une érosion irrécupérable de la légitimation du pouvoir et de l'autorité royale et, par conséquent, de l'entier appareil de l'État qui dépendait d'elle.

Face à une nouvelle loi, les robins étaient donc très méfiants et agissaient avec beaucoup de circonspection, en trouvant pendant la procédure de vérification mille "subtilitates ", mille ergoteries pour démontrer que telle loi était contraire à d'autres lois sages, produites par de précédents rois et désormais consolidées dans l'ordre juridique et dans la conscience publique. Il suffisait de relever cette incompatibilité pour avoir de leur part un argument très puissant vis-à-vis de la couronne.

\subsection{La hiérarchie des normes comme épée de Damoclès suspendue sur la tête du roi}

En effet il y avait dans ce jeu de langage technique un sous-entendu politique terrible : l'action des robins vis-à-vis de la couronne sous-entendait une menace permanente et larvée de dénoncer ouvertement - comme ils aimaient le répéter - aux " peuples gouvernés » la perversion du comportement tenu par le gouvernement ministériel, en faisant attention, dans un premier temps, à le dissocier de la personne sacrée du roi, considéré piégé ou dupé par ses ministres corrompus. ${ }^{107}$ Ce thème constitue un leitmotiv dans les sources parlementaires.

105 Cf. supra note 85.

106 Cf. Mousnier 2002, ad indicem (voix « valori»).

107 Cette dissociation ne fut plus respectée après la réforme Maupeou, lorsque la magistrature lança une offensive sans précédents contre la personne du roi, assimilée à ses ministres corrompus. Selon Darnton 1997 cette désacralisation du roi fut le turning point pour conduire au breakdown de l'État absolu et ouvrir les esprits à l'idée de la Révolution. Sur cet important argument, voir aussi l'étude très intéressante et bien conçue de Merrick 1990. 
Il n'est donc pas du tout rare de tomber sur des passages, comme celui-ci, où l'on souligne volontiers

de quelle différence il est pour un souverain de ne prêter son autorité quaux loix, ou de la prêter seulement aux volontés arbitraires d'un ministre. Dans le premier cas /.../ c'est le roi qui gouverne lui-même d'une manière équitable par le secours des loix; dans le second, c'est le ministre qui règne d'une façon bizarre sous le nom du roi. ${ }^{108}$

Dans cette stratégie de communication qui ne sadressait pas à l'establishment institutionnel mais directement à l'opinion publique, la magistrature ne se servait pas du style soutenu utilisé dans ses actes judiciaires officiaux, mais du langage, beaucoup plus efficace et compréhensible par les sujets (même ceux qui ne savaient pas lire) des images fixées dans les gravures. ${ }^{109}$ De cette manière, la magistrature réalisait un subtil et " permanent chantage » vis-à-vis du roi et de son gouvernement. 110

Le milieu parlementaire disposait à cet égard d'une formidable organisation, une redoutable machine de propagande, très efficace, dans laquelle travaillaient imprimeurs, graveurs, colporteurs, écrivains- « journalistes » et dont les magistrats savaient se servir au moment opportun et avec un cynisme impitoyable. Quand ils disaient et même criaient à tout le monde que «le roi règne, mais il ne gouverne pas ", ils entendaient exactement exprimer ce concept-là : le souverain ne doit pas toucher à l'ordre juridique établi et consolidé par la Tradition dont les dépositaires sont les juristes-magistrats. Les seuls changements admis ne pouvaient quêtre ceux qui concernaient (toujours avec le langage d'Aristote) les " accidents ", c'est-à-dire les matières qui nétaient pas « constitutionnelles ».111

Or, comme ces matières « constitutionnelles » neetaient pas fixées avec précision, mais étaient volontairement maintenues dans un certain flou, le Parlement pouvait en l'occurrence étendre ou restreindre leur portée selon un calcul

108 BPR, $L P$ 539=33, $\mathrm{f}^{\circ} 16$. Le document sort de la plume de Le Paige lui même.

109 Cf. la très belle thèse de Wachenheim 2004 et aussi ses articles Wachenheim 1998, 2001a, 2001b, 2005 et 2005-2006. Quelques témoignages concernant ce sujet aussi dans Gouzi 2007.

110 Cf. Di Donato (2003a : 440-452).

111 C'est précisément cette caractéristique qui a fait que Mousnier (2002:118-123 et 130-133), ait pu définir la constitution de l'État absolu comme une « constitution rigide » quoique productive d'effets flexibles; le droit public et ses lois fondamentales étaient considérés comme inscrits dans la « Nation française » elle-même et "gravés dans le noyau plus profond du sentiment national ». Au point que l'on pensait « qu'en elle se cachait la nature instinctive des français ». Par conséquent, il fallait que " cette loi s'impose au roi lui-même ». Non seulement il n’avait pas le pouvoir de la modifier, mais aussi « son pouvoir et son autorité dépendaient de cette Loi ». Mousnier en concluait avec une logique strictement conséquentialiste que «la loi fondamentale est donc supérieure au roi » et ceest là la raison pour laquelle « l'État est une entité supérieure au monarque lui même ». Les lois constitutionnelles sont "antérieures aux lois ordinaires et prévalent sur elles et sur le pouvoir législatif qui ne peut les abroger, ni les modifier, ni les intégrer $"$. 
dicté par sa convenance politique momentanée.112 Et souvent il savait utiliser ces amples marges de pouvoir interprétatif - qu'il sarrogeait et défendait avec acharnement - en en faisant un instrument de chantage politique, une arme pour négocier plusieurs avantages avec le roi et les ministres.

Dans les " conférences " de Versailles où les robins étaient régulièrement convoqués - comme on l'a vu - pour discuter les arrangements à apporter à une ou plusieurs lois, ils savaient faire peser le réseau de contraintes que l'interprétation juridictionnelle avait construit autour de la loi. Ces contraintes pouvaient être tout à fait juridiques, mais, si elles ne létaient pas, l'habileté des robins réussissait à les faire rentrer tout de même dans le cadre du droit, en les rattachant ainsi à la jurisdictio parlementaire. Les legum doctores mettaient alors en œuvre la hiérarchie des normes, qui opérait dans cette phase secrète du processus législatif de façon beaucoup plus efficace que si elle avait été proclamée sur le plan formel.

Tout se tenait quand même sur la base d'une formidable cohérence formelle. Et cette cohérence était destinée à couvrir le fonctionnement effectif du système. 113 L'image du roi identifié avec la loi jouait un rôle très puissant dans l'imaginaire collectif : rex est lex animata, nomos empsukos. Mais pour les juristes, qui profitaient de la nature technique du droit, la loi avait une structure (formelle et substantielle) autonome ; elle était un fragment d'une dimension ontique universelle. Elle était insérée dans un ordo juris dont les sources étaient disposées en échelle hiérarchique selon le dessein axiologique conçu par le Créateur.

Il appartenait aux magistrats, par le biais de l'interprétation juridictionnelle, d'insérer la loi ou, au contraire, de l'expulser - par incompatibilité - dans cet ordre suprême. La loi qui, après l'évaluation du Parlement, était jugée incompatible avec ces fondements constitutionnels de l'État, nétait pas une loi. Elle était annulée préventivement, c'est-à-dire avant qu'elle puisse entrer en vigueur. ${ }^{114} \mathrm{Et}$

112 Cf. Duverger (1987: 28-31).

113 C'est la raison pour laquelle une histoire formaliste du droit et des institutions n'est pas utile pour comprendre le fonctionnement réel du système juridique et politique à une époque déterminée.

114 Plusieurs auteurs manifestent des doutes quant au fait que le jugement des parlements sur les lois du roi absolu puisse être considéré comme un véritable jugement de constitutionnalité (entre autres la voix très importante de M. Troper). Récemment Rotelli (2008: 66 et 132) soppose à cet argument en vertu de la constatation que la procédure de contrôle intervenait dans le cours du procédé législatif et donc au moment où la loi nétait pas encore telle. Mais il est aisé d’objecter que le jugement de constitutionnalité des parlements d'Ancien Régime doit être classé dans la typologie des jugements de constitutionnalité preventis, c'est-à-dire délibéré avant que la loi ne rentre en vigueur. Dans ces cas-là le jugement de constitutionnalité devient en effet une partie du procédé législatif. On évite ainsi l'inconvénient technique, dont plusieurs constitutionnalistes contemporains (notamment italiens) se plaignent, de permettre à une loi que l'on soupçonne d'être inconstitutionnelle d'entrer tout de même en 
souvent les remarques d' "inconstitutionnalité » étaient formulées par les robins déjà dans la phase préventive des négociations occultes avec les ministres.

On peut alors aisément conclure que la hiérarchie des normes opérait déjà avant le contrôle formel de légalité qui se déroulait pendant la procédure de vérification. Quand l'acte législatif était soumis par le procureur général à l'assemblée des chambres du Parlement pour que le Parlement délibère sur l'enregistrement, 115 il avait souvent été déjà discuté dans les " conférences » secrètes ou du moins était-il connu à travers des canaux diplomatiques réservés qui restèrent presque toujours très actifs. Parfois, au contraire - surtout quand le roi et le gouvernement décidaient de tenter un Blitzkrieg contre le Parlement, c'est-à-dire une opération très rapide dans l'espoir de profiter d'un effet de surprise - la magistrature nétait point informée des délibérations que le gouvernement adoptait ; mais il s'agissait des cas qui donnaient lieu aux conflits les plus acharnés entre le Parlement et la Couronne. C'est justement pour éviter ou limiter fortement ces cas que la magistrature parlementaire organisa un réseau d’espionnage à l'intérieur des Conseils privés. 116

Dans ce contrôle législatif, les magistrats du Parlement faisaient rentrer non seulement la comparaison technique entre normes juridiques de différents niveaux, mais aussi (voire principalement) des facteurs que le positiviste d'aujourd'hui aurait tendance à qualifier déléments métajuridiques : le poids de la tradition et les valeurs de la société dans sa complexité, naturellement appréciées selon l'interprétation des robins eux-mêmes.

vigueur et de produire ses effets juridiques au moins pour un certain temps. Le système de contrôle préventif français est un héritage clair du système en vigueur dans l'Ancien Régime, en ce qu'il prévoit justement que la prononciation du Conseil Constitutionnel intervienne avant la promulgation de la loi. Personne ne peut douter qu'il sagit là d'un véritable jugement de constitutionnalité. Il faut en outre observer que le jugement de constitutionnalité des parlements d'Ancien Régime pouvait se réaliser aussi après l'entrée en vigueur d'une loi du roi, aussi, voire surtout, quand il avait été approuvé en lit de justice. A la première occasion processuelle dans laquelle cette loi devait être appliquée, les parlements refusaient de l'appliquer au motif qu'il s'agissait d'un texte contraire à la constitution du royaume (cf. Di Donato (2003a : 490-495)), parce qu'il avait été approuvé en violation des lois fondamentales qui prescrivaient les règles du procédé législatif, ou de même parce qu'il violait le contenu substantiel des lois fondamentales ou de lois « ordinaires » réitérées par d'autres souverains prédécesseurs et du coup qui sétaient consolidées dans le corpus du droit français ("gravé dans notre droit » est l'expression textuelle que l'on retrouve dans les sources). On peut dire, donc, que le premier grief concernait le plan de la constitutionnalité procédurale ou formelle (hiérarchie dynamique) ; le deuxième était normatif ou substantiel (hiérarchie statique).

115 Sur le rôle du procureur général au sein du Parlement dans les arrêts de règlement et dans la procédure de l'enregistrement, voir la monumentale étude de Payen 1997 et 1999.

116 Le cas le plus épatant est celui de Louis-Adrien Le Paige, leader du parti parlementaire qui réussissait à connaître, peut-on dire en temps réel, les décisions des Conseils privés et à avoir aussi la liste des ministres qui avaient voté pour ou contre la délibération : cf. Di Donato 2003a, passim. 
De ce point de vue, le contrôle sur la légitimité d'une nouvelle loi se fondait non seulement sur la comparaison entre lois ordinaires et lois fondamentales, mais plus largement entre lois ordinaires et ordo juris considéré dans sa totalité.117 Cela signifiait que le jugement de constitutionnalité effectué par les parlements tendait à nuancer les distinctions hiérarchiques rigides entre lois fondamentales et lois ordinaires, car ces dernières pouvaient elles aussi se voir conférer - à travers la consolidation de la Traditio - le poids des lois constitutionnelles.

Cette " assimilation " - le terme est d'Olivier-Martin118 - entre les deux types de lois augmentait à l'excès le rayon d'action de la jurisdictio parlementaire et qualifiait le pouvoir de la magistrature comme le pouvoir de fait suprême de l'État. Les robins devenaient aussi les interprètes exclusifs de la Traditio et pouvaient, avec les instruments analogiques et analytiques très sophistiqués dont ils disposaient, en adapter le contenu aux situations les plus différentes, en couvrant la quasi-totalité des faits juridiques susceptibles d’avoir des implications politiques. ${ }^{119}$

\subsection{La hiérarchie des normes comme présupposé indispensable pour « donner une existence juridique aux volontés du souverain » cristallisées dans la loi}

Aux yeux des magistrats de l'Ancien Régime cette osmose entre le droit formel et la mentalité sociale assurée à travers la charnière de l'interprétation jurisprudentielle paraissait une vérité tellement évidente qu'ils la considéraient comme «naturelle».

Le droit était (et devait être) l'expression la plus élevée de l'ordre cosmique. Il assurait la reproduction dans l'organisation de la société de l'ordre universel de la nature voulu par Dieu. L'État « de droit » était le seul organisme qui pouvait donc assurer cette liaison entre la sphère religieuse et la sphère humaine. Le droit dans cette mentalité était divin et par conséquent humain. L'harmonie entre la Veritas métaphysique et la Ratio mondaine, ou autrement dit entre le Verbum et la Res (publica) était assurée par cette charnière fondamentale, l'ordo juris, dont les interprètes autorisés, les juges, étaient les uniques agents. Un roi sans droit nétait qu’un tyran. Et un État sans magistrature n’aurait eu aucune garantie de pouvoir rester longtemps dans la civilisation. ${ }^{120}$ Cette dernière était

117 Cf. Di Donato (2004 : passim; et 2005 : spécialement 77-82).

118 À propos de l'" assimilation des lois ordinaires aux lois fondamentales », Olivier-Martin (1988 : ch. I, 24-52), soulignait l' « astuce » de la magistrature qui parlait « des lois, tout simplement, et non plus des lois constitutives " (Olivier-Martin $1988: 29$ ).

119 Pour le développement de cette interprétation je renvoie à mes essais : Di Donato 2004, 2005 et 2007.

120 Sur ce concept classique de la culture occidentale, aujourd'hui soumis à une pénétrante analyse critique (voir à ce sujet Binoche 2005 et 2007), cf. les ouvrages classiques de Braudel 1993 et Elias 1973 et l'essai, très précis de Starobinski 1989. 
véhiculée par le droit et du coup s'avérait inséparable de celui-ci. Si l'État monarchique était donc par excellence l'instrument capable de rendre la société " civilisée ", cela était notamment le fait de la magistrature qui faisait respecter le droit et se posait en lien privilégié entre ciel et terre.

Cette vision panjuridique du monde est illustrée de façon exemplaire dans un passage d'une importance capitale tiré d'un manuscrit rédigé autour de 1754-55 par Charles-François-Henri de Revol, alors conseiller puis (à partir de 1758) président-à-mortier au Parlement de Paris. ${ }^{121}$ Cet important magistrat insistait sur le fait qu'il fallait « faire sentir combien les formes dont le Parlement est le gardien sont au moins aussy essentielles pour le monarque que pour les sujets ». C’était à ses yeux un "dogme politique » qui faisait naître «la nécessité de le faire paroître dans toute sa force » en lui donnant le " plus grand degré d'évidence".

De cette constatation de départ dérivait une ontologie des valeurs politiques du royaume qui faisait une avec les formes juridiques dont le Parlement était le maître. Ainsi ces formes étaient « les plus essentielles et les plus prétieuses [sic] » colonnes de l'État et par conséquent le jugement politique du Parlement, qui consistait symboliquement dans l'apposition de son "sceau " aux textes normatifs présentés par le roi et ses ministres, était indispensable "pour donner une existence juridique aux volontés du souverain consignées dans divers instruments, comme édits, déclarations, arrests du Conseil ».122 Sans l'accord du Parlement, la volonté du roi, fondement de la loi, nexistait même pas, et sa manifestation restait tamquam non esset.

Lévaluation portée sur les lois de la part de la magistrature parlementaire appartenait donc à une typologie de jugement tout à fait particulière. Cétait en effet un jugement qui était fondé sur des points de repère complètement hétérogènes, et par conséquent incontrôlables car ils ne pouvaient être fixés comme objets spécifiques et pour ainsi dire 'visibles'. Il s'approchait de l'arbitraire. C'est à travers ce processus, d'ailleurs, que dans l'expérience juridique de toute l'Europe médiévale et moderne "l'intrinsèque ambiguité des sources du droit /.../ et leur célébrée, solide, extrinsèque objectivité » a été « l'instrument primaire de la médiation sociale menée par le pouvoir juridique ».123

121 Cf. Bluche (1986: 221-222, 271, 273-274 et 386).

122 Bibliothèque de la Société de Port-Royal (BPR), fonds Le Paige, vol. n. 534, pièce n. 33. L'expression sort de la plume de Revol (qui, rappelons-le, était parmi les disciples les plus étroits de Louis-Adrien Le Paige), mais elle est ouvertement empruntée à louvrage plus représentatif de l'avocat, les célèbres Lettres historiques sur les fonctions essentielles du Parlement; sur le droit des Pairs, et sur les loix fondamentales du Royaume, 2 vols., aux dépens de la Compagnie, Amsterdam [mais en réalité imprimées dans la typographie clandestine de Le Paige implantée dans l'enclos du Temple à Paris] : I, 1753; II, 1754 (= BNF, LD-4.2563; BPR, LP $534=29$ et $L P 2133-2135)$ : cf. Di Donato (2003a : 454).

123 Ajello (1990: 8). 
Ainsi les « contrôleurs-vigilants » jugeaient sans appel si une loi du roi violait des principes supérieurs qu'eux-mêmes établissaient et considéraient sacrés et intangibles. C'était donc le pouvoir juridictionnel qui faisait exister la hiérarchie des normes. Celle-ci n'existait pas objectivement, en dehors de l'action de la magistrature.

Dans les moments de crise politique (par exemple au cours du XVIIIème siècle pendant le règne de Louis $\mathrm{XV}$ ), ces doctrines émergeaient avec force et donnaient lieu à de véritable guerres de pamphlets. Ce que les magistrats remarquaient avec insistance étaient que la loi que le Parlement examinait ne rentrait pas en vigueur tant quelle nétait pas enregistrée. Au moment où le roi la signait, elle nétait pas encore - selon la doctrine parlementaire - une véritable loi, mais était seulement un simple " projet de loi » que le roi présentait au Parlement pour en obtenir la pleine légitimation. Le principe constitutionnel de l'enregistrement donnait lieu à une procédure nécessaire quaucun roi n’avait jamais osé remettre en cause. Louis XIV, lui-même, n’avait que déplacé le droit de remontrance après l'enregistrement, mais il n'avait pas pu le supprimer toutcourt. 124

De cette continuité institutionnelle, qui avait résisté même dans les moments les plus difficiles de l'histoire de l'État, ${ }^{125}$ les robins déduisaient que l'ordre juridique de l'État s'imposait aux rois eux-mêmes et qu'il était fondé sur une échelle hiérarchique de normes dont la haute magistrature était la seule garante. C'était justement cette affirmation de lexistence de la hiérarchie des normes qui faisait ressentir aux robins la légitimité de s'opposer, avec l'entêtement dont ils étaient capables, à toute tentative de rendre le pouvoir du roi effectivement «absolu». Pour les parlements, il devait au contraire rester un pouvoir symbolique. Ils accusaient immédiatement de " tyrannie » et de « despotisme »126 toute tentative de lui conférer de l'effectivité. Plusieurs rois - et le jeune Louis XV notamment - furent terrorisés par ces mots et par la crainte de pouvoir être accusés de gouverner comme des «tyrans». Ils ne voulaient pas être despotes. Ils voulaient être rois. 127

124 Pour un profil synthétique et efficace du débat historiographique sur la tentative échouée de Louis XIV de changer la constitution du royaume, cf. Un débat à plusieurs voix sur le concept d'« absolutisme» (Mousnier 2002 : 99-109) avec la participation, entre autres, de Méthivier, Reinach, Lajusan, Bluche, Esmonin, Hyslop, de Berthier, Lévy, Lefebvre, Gadrat, Soboul. Ce débat eut lieu le 6 novembre 1955 au siège de la « Société d'Histoire Moderne » à Paris.

125 La rhétorique robine arriva à peindre ces moments recourant à l'image biblique de la « traversée dans le désert » du peuple de Dieu en marche vers la Terre Promise : cf. Di Donato (2003a : 158-171) ; Di Donato (2003c : 101-122).

126 Une ample réflexion sur cet argument, centrale dans l'histoire des doctrines politiques et juridiques, a été récemment proposée par plusieurs auteurs rassemblés par Felice (2001-2002).

127 Cf., pour l'époque de Louis le-Bien-aimé, les ouvrages d’Antoine 1986 ; 1989. Voir aussi Bluche 2000. 
Pour être roi et non pas tyran, il fallait avant tout respecter la hiérarchie des normes. La volonté du roi était, en effet, le fondement de la loi. Mais la loi ne pouvait pas être hors la loi. Les juristes savaient d'ailleurs jouer de cet aspect psychologique avec subtilité et beaucoup de nuances dans leurs rapports, souvent tendus, avec le souverain. Au XVIIIème siècle, pendant les troubles les plus acharnés engendrés par la lutte parlementaire, 128 des concepts tels que " despotisme ", " constitution », " contrôle parlementaire sur les lois du roi »-ce qui impliquait l'existence d'une véritable hiérarchie des normes - furent utilisés comme des entités théoriques et politiques liées entre elles. ${ }^{129}$ Une grande quantité de sources pourraient être citées pour montrer l'existence concrète de cette pyramide hiérarchique qui renvoie directement à la façon dêtre - à la fois doctrinale, stratégique et psychologique - de la robe parlementaire. 130

Une seule mérite dêtre reproduite ici qui paraît particulièrement probante. Dans une longue "dissertation » manuscrite rédigée en 1771 (en pleine mise en place de la réforme Maupeou) " pour les princes du sang ", Louis-Adrien Le Paige, 131 le leader et idéologue du 'parti' parlementaire, soutient que le fondement constitutionnel du royaume est fondé sur le corpus normatif tiré par la «Tradition ». Il cite plusieurs formules de Bossuet et de Massillon. Suivons-le attentivement dans sa défense longue et passionnée de la "spécificité juridique de l'État français ", expression qui signifie pour lui tout simplement un État gouverné et contrôlé par la «juridiction des magistrats en robe ».

De ce rôle décisif de la jurisprudence parlementaire dans le cadre de la structure originaire de l'État (le Parlement est pour lui « aussi ancien que la monarchie elle-même ») il fait dériver la nécessité d'un contrôle de constitutionnalité sur les lois du roi en l'appuyant, bien évidemment, sur l'idée d'une hiérarchie des normes dans l'ordre juridique du royaume :132

Gardés - écrit-il - les ancien[n]es maximes sur les quel[1]es la monarchie a été fondée et soutenüe / .../ des son origine par lordre de la divine providence, la meilleur constitution d'État qui soit possible, et la plus conforme a cel[1]et que Dieu même a établie. On doit donc sattacher à la forme du gouvernement établie. Il doit demeurer dans létat auquel un longtems a accoutumé le peuple. On doit le suivre com[m]e un ordre divin, parce que Dieu est un Dieu de paix qui veut la tranquillité des choses humaines. Ainsi il est très véritable, Sire, que vous êtes un monarque dépendant de Dieu seul.

128 Outre aux livres désormais classiques de Diaz 1962 et de Alatri 1977, je me limite ici à rappeler, quelques ouvrages plus récents : Rogister 1995 ; Swann 1995 ; Van Kley 2002 ; Vergne 2006. Un éventail bibliographique sur l'argument dans mon livre : Di Donato (2003a : 821861).

129 Cf. Schmale $1987 ; 1990$.

130 Je renvoie le lecteur intéressé par ces nombreuses sources à patienter dans l'attente d'un ouvrage en deux tomes que je suis en train de rédiger sur l'histoire du conflit entre magistrature et politique.

131 Cf. plus haut, note 42.

132 Cf. plus haut, note 43. 
Mais il est très véritable aussi que vous êtes un monarque lié par des lois fondamentales, et que vous devés garder les ancien[n]es maximes de votre monarchie. C’est-àdire que vous nêtes point un monarque qui puisse s'assimiler aux monarques d'Asie, mais un monarque françois. Vous nêtes point un sultan, mais un roi de France. Et c'est, Sire, ce qui fait l'ap[p]ui inébranlable de votre thrône. Car ces monarques d'Asie sont souvent renversés /.../ tôt ou tard. Il est de même incontestable que vous tenés votre autorité de Dieu: c'est par le rang de primogeniture où il vous a fait naître, qu'il vous l'a conférée. Cet[t]et autorité vient de Dieu. Tous vos sujets le recon[n]oissent. Mais quel[1]et autorité Dieu vous-a-t-il don[n]ée? Cel[1]et d’un monarque. Et de quel[1]et nature de monarchie? Ce n'est pas cel[1]et d'un monarque d'Asie ni d'un sultan. C'est cel[1]et d'un monarque françois, assujeti par conséquent à la constitution de la monarchie françoise. Vous ne pouvés donc, Sire, changer ni altérer cet[t]et constitution françoise sans dénaturer l'autorité que vous tenés de Dieu. La changer, ce seret [sic...] exiger de la soumission d'un peuple plus que ce que les loix permet[t]ent aux rois d'en exiger, c'est nêtre plus ses pères et ses protecteurs, mais ses ennemis et ses op[p]resseurs: c'est ne plus régner sur ses sujets, c'est les subjuguer. ${ }^{133}$

Hiérarchie des normes, droit divin-naturel, tradition, civilisation : voilà les ingrédients fondamentaux de la thèse parlementaire. Tout le problème historiographique qui concerne le chercheur intéressé de reconstruire le fonctionnement effectif du système juridique, politique et institutionnel de l'Ancien Régime consiste à savoir si et dans quelle mesure la magistrature réussissait à traduire en pratique ses propos ou si, au contraire, il ne s'agissait que d'un programme idéologique et politique purement théorique, destiné à rester dans la sphère des desiderata qui, par définition, n’arrivent jamais à se réaliser.

\section{LA CONSTRUCTION D'UNE STRATÉGIE DU DISCOURS JURIDIQUE VISANT À LA MISE EN PLACE D'UNE HIÉRARCHIE NORMATIVE STATIQUE ET DYNAMIQUE ANTE LITERAM}

Dans la procédure d'évaluation complexe que la magistrature parlementaire mettait en place pour exercer le contrôle de constitutionnalité, les lois fondamentales restaient, certes, le point de repère majeur, l'instrument le plus pénétrant dont les robins disposaient.

Dans les doctrines qui visaient à donner un fondement de légitimité à ce type de jugement sur les lois du roi il n'est évidemment pas facile de repérer une théorie claire qui traite d'une hiérarchie normative allant au-delà des lois fondamentales. Les théoriciens philo-parlementaires savaient parfaitement que la mise en place d'un discours trop manifeste concernant une juridiction prati-

133 BPR, $L P$ 569=75. Ce passage est tiré d’un « projét de mémoire ou let[t]re au roi » rédigé par Le Paige sur commission des princes du sang et qui « n’a pas eu lieu, quoiqu’arreté et convenu par les princes". 
quement sans limites aurait rencontré une opposition très dure de la part de la couronne et de ses partisans. Les robins étaient bien conscients que cela aurait été un mouvement à effet contraire.

Par conséquent l'historien qui veut développer une analyse profonde du phénomène en question doit être attentif à ne pas absorber intégralement le discours parlementaire en le prenant à la lettre sans rien trier, mais il doit apprendre à fouiller en-dessous de la surface pour savoir lire entre les lignes et dépister les significations réelles qui se cachent sous des formules apparemment ordinaires et sous les déclarations de principe. Ainsi il faut déceler le vrai sens - souvent polysémique - des concepts que ces théories constitutionnelles illustrent avec une admirable emphase. Cette opération s'avèrerait impossible sans une constante attention à la situation politique réelle qui se détermine au moment de la rédaction du texte, c'est-a-dire sans considérer les relations effectives qui déterminent la production du discours. 134

La construction théorique de la doctrine parlementaire insiste presque entièrement sur l'importance des lois fondamentales. ${ }^{135}$ Mais ce n'est qu'une partie de la stratégie discursive et politique du milieu de robe. En effet la perception de la chose demande beaucoup de subtilité : il s'agit de saisir la différence entre, d'une part, l'évaluation d'un contraste d'une loi du roi avec un principe de droit naturel ou divin ou encore avec les lois fondamentales et, d'autre part, lévaluation d'un contraste d'une loi du roi avec une autre loi ou d'autres lois 'ordinaires' mais munies désormais d'une sorte de force supplémentaire qui dérivait de leur durée, c'est-à-dire de l'acquisition d'un caractère 'traditionnel'.

Cette différence était au fondement d'un principe toujours clair tantôt aux juristes théoriciens tantôt aux magistrats qui avaient la tâche de procéder à léviction d'une norme jugée inconstitutionnelle. Mais cela nétait vrai que sur le plan théorique. Dans la pratique du système politico-judiciaire la différence entre ces deux situations était beaucoup moins nette, car normalement la magistrature décidait d'abord qu'une loi méritait dêttre annulée et seulement après elle cherchait l'argument juridique formel qui aurait justifié la décision. Et si l'argument réel se fondait sur la violation non pas d'une loi fondamentale mais d'une autre loi 'ordinaire' que le Parlement considérait supérieure, le résultat n’aurait pas changé pour autant : la nouvelle loi du roi n’aurait tout de même pas été enregistrée.

Plusieurs possibilités souvraient donc aux juges parlementaires. Si la loi du roi était en conflit direct et manifeste avec une ou plusieurs des lois fondamentales, alors le Parlement procédait à une " annulation " directe en se refusant simplement à enregistrer l'acte royal et en le renvoyant au roi avec des remontrances dans lesquelles il donnait toutes ses explications et ses arguments. Par

134 Voir plus haut note 3.

135 Cf. Lemaire 1907; Cocatre-Zilgien (1963, spécialement 62-69) ; Lovisi-Saguez 1983. 
exemple, le Parlement n'aurait jamais pu enregistrer l'avènement au trône d'une femme ou d'un hérétique, ou permettre l'aliénation vénale du domaine royal par pure manifestation de volonté du monarque ou par son intention de "vendre » un territoire pour augmenter le budget de l'État.

Mais il en était de même pour les tentatives de modifier la procédure de l'enregistrement. Le Paige l'explique clairement, en utilisant un argument qui pourrait être défini, avec un langage kelsénien ex ante, de relatif à la " hiérarchie dynamique " des normes juridiques. Cet argument lepaigien concerne les itinera du processus législatif. La procédure établie pour créer une nouvelle loi était fixée par d'autres lois. Ces dernières ne pouvaient, donc, quêtre de rang supérieur. Ainsi, attaquer l'institut de l'enregistrement, pivot de la procédure, signifiait « attaquer les loix qui l'ordonnent ainsi ».136

Le Paige trace ici une sorte de théorie constitutionnelle de l'ordre juridique dont l'existence dépendait non seulement de la présence de lois ordonnées selon une échelle hiérarchique (on est là face à une véritable " hiérarchie statique " ante literam des normes juridiques), 137 mais aussi de l'existence d'un pouvoir juridictionnel mis dans les conditions d'assurer le respect des procédures de formation de l'acte législatif (ce qui serait qualifié aujourd'hui de « hiérarchie dynamique »). 138

Des institutions comme la vérification et l'enregistrement impliquaient donc l'existence non seulement d'une hiérarchie statique, mais aussi d'une hiérarchie dynamique des sources du droit, car elles réglaient la procédure de formation des lois. Vérification et enregistrement étaient, en d'autres termes, des instruments de contrôle par lesquels les robins pouvaient formuler un jugement sur une loi du roi, conçue comme un acte juridique formel que l'on reconnaissait puisqu'il était réalisé dans le respect de procédures établies à l’avance.

Grâce à la « hiérarchie statique » le Parlement procédait à l'examen du contenu normatif des textes délibérés par le gouvernement royal, tandis que grâce à la " hiérarchie dynamique " il arrivait à se prononcer sur la question préalable qui consistait à savoir si le nouvel acte pouvait être considéré légitimement comme une « loi » de l'État au regard du processus de formation avec lequel il avait été créé.

Les robins ont toujours insisté sur ce point qu'ils considéraient comme un pilier fondamental du droit public non seulement français mais « universel et absolu ».139 Une loi - disaient-ils - créée en violation des normes qui établissaient comment il fallait créer les lois, ne peut absolument pas être considérée comme

136 BPR, LP 580-ter $=207$.

137 Sur cet argument, cf. Troper (1998: 154-164).

138 Troper 1994.

139 BPR, $L P 539=179$. 
valide dans aucun ordre juridique. S’appuyant sur ce présupposé logique, les legum doctores affirmaient que la " constitution du royaume " prescrivait que la procédure de la vérification parlementaire des actes royaux devait être considérée comme « essentielle» dans la procédure législative. Par conséquent, une loi non enregistrée ne pouvait pas être considérée comme une « loi » car elle avait été créée en violation de la procédure prévue par le « droit public de la Nation ». Ce droit public contenait donc des règles juridiques qui devaient être assimilées entièrement aux lois fondamentales.

Il en était de même - cela va presque sans dire - pour la loi enregistrée dans un « lit de justice ». Selon la thèse parlementaire, tous les organes munis de juridiction devaient refuser d'appliquer une loi enregistrée en lit de justice car elle était ouvertement inconstitutionnelle pour motif de violation de la procédure prévue pour l'approbation d'une loi. ${ }^{140}$ Le Paige souligna à plusieurs reprises cet aspect et invita tous les parlements à considérer " non valablement enregistrés " et par conséquent " non avenus " tous les actes royaux (" édits, déclarations etc. ») qui avaient été " transcrits forcément » en lit de justice. ${ }^{141}$ «Un lit de j[ustice] - dit-il - ne finit rien » et « les choses ne sont pas plus avancées quauparavant ». ${ }^{142}$ Cela signifiait que " dans le ressort du Parl[ement] les juges inférieurs refuseront d'enregîtrer les édits $\operatorname{com}[\mathrm{m}]$ e nétant pas enregîtrés au Parl[ement] ».143 Et la même chose aurait dû advenir « de la part des autres parl[ements] ».144

Le lit de justice déterminait un terrible vulnus constitutionnel porté à la « Tradition » et au juste ordre des choses établi par la Providence divine pour le «salut » de l'État. La volonté du souverain imposée brutalement dans le lit de justice violait gravement les droits des sujets. Ce geste devait donc être considéré comme un acte de " puissance arbitraire » qui replongeait le royaume dans le stade de pré-civilisation dans lequel on navait pas encore instauré lordre juridique. Responsable de transgresser ostensiblement les normes constitutionnelles du royaume, le lit de justice était comparé à un « acte de barbarie » qui déterminait une très forte et dangereuse " alarme [dans] le public ».145 Contraindre les magistrats à manifester leur consentement à l'enregistrement signifiait violer

140 Le Paige $1753-1754 ; 1754 b ; 1755$ et surtout 1756.

141 BPR, $L P$ 558=72. Cette "notule " manuscrite parait en marge de la copie imprimée d'une « déclaration du roi concernant le cadastre général, la liquidation et le remboursement des dettes de l'État, donnée à Versailles le 21 novembre 1763 ».

142 BPR, LP 539=179: «Billet de moi à monsieur le prince de Conti. 25 aout 1756 ». Des documents comme celui-ci et celui qui a été cité dans la note précédente sont à mon avis d'une exceptionnelle valeur historiographique, car ils condensent toute l'idéologie de la robe d'Ancien Régime et contribuent à expliquer des aspects obscurs concernant les origines du conflit entre magistrature et pouvoir politique.

143 BPR, $L P$ 539=179 : " Billet de moi à monsieur le prince de Conti. 25 aout 1756 ».

144 BPR, $L P$ 539=179 : « Billet de moi à monsieur le prince de Conti. 25 aout 1756 ».

145 BPR, LP 539=179 : « Billet de moi à monsieur le prince de Conti. 25 aout 1756 ». 
ouvertement le droit public du royaume. Il fallait pour autant « protester contre tout ce qui s'est fait au lit de j[ustice] com[m]e contraire aux loix du r[oi] ». ${ }^{146}$

Cette ligne théorique, constamment défendue, était naturellement vouée à se renforcer pendant la réforme Maupeou. Le 27 avril 1771, par exemple, Le Paige écrivait, dans un commentaire envoyé à son disciple de Murard, magistrat au Parlement de Paris ${ }^{147}$ :

Je ne me reconcilie p[oint] avec ces transcriptions forcées. Elles reclament contrelles mêmes. Le Roi a l'exécution dans sa main par la force. Mais il a contre lui la légalité; et ces transcriptions sont touj[ours] illégales. ${ }^{148}$

La pratique instaurée par le gouvernement déracinait du droit public du royaume des conventions coutumières invétérées :

Je suis toujours arreté - continuait l'avocat - sur cet enregistr[ement] d'emblée, qui est illégal et dérisoire s'il est fait sans délibération, et pis qu'illégal s'il est fait contre le résultat de la délibération [négative]. ${ }^{149}$

C’était une conclusion soutenue à son avis par toute la majeure doctrine juridique française :

Nos auteurs disent que la loi est affichée par là pour mauvaise; quelle est decrédité chez les peuples ; et que tôt ou tard le prince l'abandon[n]e. Il n'est donc pas possibles de tenir cette manière ni pour légale ni pour légitime.150

La seule exception admissible au principe de légalité était l'état de nécessité, qui pour sa nature devait être strictement limité à un événement exceptionnel et imprévu : «Qu'on viole les formes légales quand le salut public qui est la loi suprême l'exige ». Dans ce cas là, en effet, « la loi est violée, mais son infraction est causée par les circonstances ». Toutefois « il faut cet[t]e nécéssité du salut public; et cet[t]e nécéssité ne peut être que rare ».151 Presque un mois après il revint sur l'argument avec une vigueur encore plus forte :

Il n’y a q[ue] ces transcriptions illégales. Mais je désirerois qu’on fit voir: $1^{\circ}$ que l’enregistrement délibéré est une des formes publiq[ues] de l'Etat sagement établies; $2^{\circ}$ que toute loi non délibéré, peut être bon[n]e, mais q[ue] les formes publ[iques] n'y sont pas gardées; ce que les Rois ont recon[n] u, même sous le c[ardinal] de Richelieu; $3^{\circ}$ que les loix publiées après cet $[\mathrm{t}$ ]e délibération, mais contre le résultat de la délibér[ation] peuvent encore être bon[n]es, les parl[ements] pouvant se tromper; mais que les formes publiq[ues] ne sont pas moins blessées; $4^{\circ} \mathrm{q}[\mathrm{ue}]$ le Roi non seulement a certainement

146 BPR, $L P$ 539=179 : «Billet de moi à monsieur le prince de Conti. 25 aout 1756 ».

147 Alexandre-François de Murard fut conseiller au Parlement de Paris en 1738 et présidentà-mortier depuis 1758. Il était, avec de Revol et le président Durey de Meynières, parmi les robins les plus étroitement liés à Le Paige : cf. Bluche (1986 : 188, 195, 221-222).

148 BPR, LP 42, fo 431.

149 BPR, $L P 42$, fos 431-432.

150 BPR, $L P 42$, fo 432.

151 BPR, $L P 42$, f 432.

revue de théorie constitutionnelle et de philosophie du droit 
le pouvoir par la force de passer outre, mais que dans le cas où le salut public l'exige et où le secret d'Etat ne lui permet pas d'exposer ses raisons, ce dont lui seul est juge, il en a très réellement le droit; mais qu'il n'y a que le succès qui puisse faire cesser aux yeux de la nation les précautions que ces voies d'autorité inspirent aux peuples contre la loi, et vérifier ce cas d'exception; que ces précautions sont touj[ours] fâcheuses, et ces voies par conséquent touj[ours] dangereuses; que ces voies justes alors ne sont qu'un exception légitime à une règle très sage; que ces exceptions ne peuvent être que très rares, et qu'il est de l'intérêt de l'Etat et du Thrône qu'elles soient en effet très rares /.../ L'enregistrement sup[p]ose un examen; et agir ou sans examen ou contre le resultat de cet examen, c'est agir contre lâme et la let[t]re du sage établissement sauf le cas du salut public qui est la loi des loix, mais qui ne peut être que rare, et que le succès seul justifie. ${ }^{152}$

Agir différemment, comme le prétendait la couronne, signifiait réduire « l'enregistrement» à rien de plus qu' " une vaine formalité, /.../ un acte stérile qui /... / n'ajoute à la Loi que l'appareil d'une publicité qu’elle peut acquérir par tant d'autres moyens ». Bref, l'enregistrement ne serait devenu « qu'un vain simulacre qu’a laissé subsister la tolérance de nos Rois, et qui doit tomber à l'instant où il leur plaira de l'ordonner ». .153

152 BPR, LP 42, fo 433 .

153 Bibliothèque du Sénat, fonds Boissy d’Anglas, vol. 805, fo 157r. Olivier-Martin 1988, chap. I, voyait dans cette prétention de l'" enregistrement libre " une tentative de " modification grave apportée à la constitution de la monarchie» (Olivier-Martin $1988: 28$ ). Toutefois, il admettait aussi que l'on pouvait parler d'exécution de la « loi du roi par elle-même » seulement jusqu'aux XIIIe et XIVe siècles, c'est-à-dire " tant que la pratique de l'enregistrement ne s'est pas implantée » (Oliver-Martin 1988 : 24). Ensuite « le roi s'est incliné devant l’obstination des cours » et il leur a régulièrement soumis la " vérification de toutes ses lois générales », jusqu’à devenir "impuissant » puisque "son autorité de législateur est désormais subordonnée à la décision d'une cour composée de ses officiers » (Olivier-Martin $1988: 28$ ). C'est pour cela que l'on a du mal à comprendre le sens de la conviction du même auteur suivant laquelle ce ne serait seulement qu'après 1750 que les cours auraient commencé à utiliser leur prérogative d'enregistrer les actes royaux comme un pouvoir «menaçant pour l'autorité du roi » (Olivier-Martin 1988 : 25). La description diachronique que lui-même fournit du phénomène donne plutôt l'impression de se trouver face à une crise structurelle, à un conflit permanent dans le cœur de l'État monarchique-absolu, un conflit qui se développe au fur et à mesure de l'expansion des fonctions publiques et de la croissance de l'appareil d'État. Peut-être que l'explication est à chercher dans l'idéologie du grand historien-juriste : même s'il observait que la " pratique de lenregistrement » conduisait le système dans la direction d'une augmentation nette du pouvoir politique de la magistrature, sa foi 'monarchiste' lui imposait l'impératif éthico-politique de sauver quand même le fondement essentiel de l'" autorité du souverain ». Et il est encore intéressant d’observer la contorsion logique de sa description pour sauver le "principe » quoiqu'il ne s’avère point dans la réalité historique : « La loi - écrivait-il -, enregistrée d'autorité, était tout de même obligatoire. Sans doute certaines cours sobstinaient à ne pas appliquer, dans des cas concrets, une loi enregistrée d’autorité; la loi, ou du moins certaines de ses dispositions, pouvait tomber en désuétude; mais le roi avait des moyens de faire appliquer la loi, en cassant dans son Conseil l'arrêt qui la violait. Pour ne pas prolonger la querelle, le roi pouvait fermer les yeux. Mais le principe subsistait. Le roi avait le dernier mot et son autorité, dont il n'usait pas à tout propos, restait sauve » (OlivierMartin 1988 : 27). Sur le même argument, voir aussi Olivier-Martin (1997a : 210-224, 290 - 
Que l'enregistrement entraîne une hiérarchie dynamique (en plus de celle statique) des normes juridiques ne paraît donc pas douteux. Il est néanmoins important de relever que les deux hiérarchies normatives - tant la statique que la dynamique - attribuaient à la magistrature un énorme pouvoir d'intervention sur les actes législatifs et gouvernementaux. Et c'est en premier lieu pour cette raison que les juristes de l'Ancien Régime considéraient l'ordre juridique selon une disposition hiérarchisée.

Un problème plus grave se posait lorsque la loi du roi ne violait visiblement aucun principe des lois fondamentales. Et pourtant le Parlement, s'il la considérait "incommode ", la déclarait aussi illégitime, car, disait-il, elle violait tout de même des principes « de rang constitutionnel ». Il y avait là plusieurs sous-cas possibles qui sont tout-à-fait intéressants pour observer comment la hiérarchie des normes opérait concrètement. Ou bien la loi, tout en ne violant pas directement les lois fondamentales, se prêtait toutefois à une interprétation selon laquelle son application arrivait à produire un effet juridique en conflit avec des principes constitutionnels; ou bien la loi, tout en ne violant pas directement les lois fondamentales, contrastait avec d'autres lois qui avaient consolidé quelques principes juridiques, politiques, conventionnels ou sociaux que la magistrature appréciait comme aussi «fondamentaux » que les lois fondamentales elles-mêmes ; ou bien encore, la loi, tout en ne violant pas directement les lois fondamentales ni aucune autre loi précédente, affirmait toutefois simplement des principes «nouveaux » qui étaient, en tant que tels, très mal vus, car «faire nouveauté » était considéré dans la vision du monde dominante de l'Ancien Régime - une vision dont les juristes se considéraient être les gardiens-vigilants - comme un mal en soi.

Il est fort probable que, dans un cas pareil, la construction du discours parlementaire - que l'on aurait bien sûr déversé dans des épaisses remontrances - ne se fonde pas ouvertement sur la remarque d'incompatibilité avec une loi précédente (ce qui aurait violé ouvertement le principe de fond de la monarchie absolue selon lequel la volonté du roi fait la loi et par conséquent que la volonté législative d'un roi pouvait déroger ou abroger une loi précédente), mais qu'elle se structure autour d'un revêtement conceptuel apparemment beaucoup plus complexe, dans lequel on mettait en place tout l'arsenal argumentatif dont la technique juridique et la savante rhétorique des exégètes du droit étaient capables.

Le Parlement pouvait arriver jusqu'à recourir au stratagème de s'autosaisir pour étendre, à travers une extension analogique, son pouvoir d'intervention.

358 et spécialement 223) où il affirme sans nuances que tout compte fait «la souveraineté reste intacte ». L'historiographie juridique a depuis fait quelques progrès interprétatifs : sur l'évolution de l'enregistrement dans la pratique institutionnelle, cf. Vilar-Berrogain (1958 : spécialement 13-28), et plus récemment Gojosso 2002 ; Renoux-Zagamé (2003 : 212-43). 
C'est ainsi qu'il réussissait à soulever une question de constitutionnalité à partir d'une cause particulière. Il devenait dans ces cas là le judex a quo de soi-même. Dans d’autres cas, il pouvait évoquer la cause si elle était pendante devant un autre tribunal, lorsqu'on relevait quelle pouvait contenir un germe susceptible d'entraîner une question constitutionnelle ou qui pouvait revêtir une importance politique.

La jurisprudence devenait ainsi, dans la conception parlementaire du droit et de l'État, le fondement ontique de l'ordre juridique. Le Parlement n'appliquait la loi quà partir du moment où il en reformulait les énoncés tantôt à travers la tentative d'influencer la formulation textuelle originaire tantôt à travers son interprétation successive dans l'expérience processuelle. "Appliquer » et " créer » du droit voulait dire la même chose. Lorsqu'il exerçait ce pouvoir le Parlement effectuait contextuellement deux différentes opérations : d’un côté il réalisait le contrôle de constitutionnalité, c'est-à-dire une vérification concernant la correspondance des normes de niveau inférieur à d'autres considérées de niveau supérieur (ces dernières nétant pas écrites offraient à l'exégète un marge pratiquement illimitée d'interprétation/création); d'un autre côté il participait activement (quoique sous les apparences du jugement ex post) à la fonction nomothétique.

La doctrine de droit public de l'avocat Le Paige, certainement la plus élaborée de l'État monarchique absolu et qui s'intéresse le plus à la hiérarchie des normes, établit une étroite relation entre lois fondamentales et ordre juridique, voire entre jurisdictio et Respublica. Pour lui, ces termes étaient fortement entrelacés et il y avait entre eux un rapport de réciprocité. Pour Le Paige il n'y a pas d'«État » sans « droit » et il ne peut y avoir aucun «droit» qui ne soit hiérarchiquement ordonné sur la base de l'activité interprétative de la magistrature.

Pour appliquer la loi, voire pour la faire exister dans la réalité et pas uniquement dans la forme juridique, la manifestation de volonté d'un souverain et les délibérations de son Conseil ne suffisaient pas. Il fallait la jurisdictio du Parlement. La fonction de jus dicere ne pouvait point se réduire à la simple « application » de normes préexistantes. La jurisdictio ne pouvait pas être séparée des normes juridiques. Elle ne les appliquait pas. Elle les créait. Elle en constituait l'essence. Juger ne signifiait pas déclarer le contenu d'un texte qui existait déjà. Juger signifiait produire le vrai sens de lénoncé textuel. La norme nétait donc pas du tout dans la volonté du roi, mais dans l'interprétation du Parlement au moment où il l'appliquait.

C’était la conviction profondément enracinée de Le Paige qui insista toute sa vie dans la défense de cette conception apparemment technique de l'ordre juridique mais qui impliquait en réalité une vision politique lato sensu du monde. Héraut de l'idéologie typique du jurisconsulte de l'Ancien Régime et héritier d'une très longue tradition, l'avocat pensait, comme l'avait dit La Roche Flavin, 
que « les parlements nont pas été seulement établis pour le jugement des causes et procès entre parties privées ; mais ils ont été aussi destinés aux affaires publiques ». 154 De même Le Paige prêchait pour que le « jugement [du Parlement], ferme, solide, décisif dans les affaires " puisse sélargir jusqu' " aux vues de la politique ». ${ }^{155}$ Ainsi pouvait-il affirmer que « la juridiction du Parlement était universelle pour toutes les matières »156 et que, dès le Moyen Âge, cette puissance juridictionnelle avait été considérée par les rois eux-mêmes comme « une marque essentielle de souveraineté ».157

\section{CONCLUSION : LA HIÉRARCHIE DES NORMES PILIER DE L'ÉTAT ABSOLU DANS LA CONCEPTION DE LA ROBE}

La hiérarchie des normes - et avant tout celle qui fondait la « hiérarchie dynamique " des normes juridiques, en prescrivant le droit de vérification du Parlement sur tous les actes législatifs du souverain - était donc le fondement premier de l'État absolu. Ce dernier était tout de même un État de droit. Et le droit produisait ses règles, mais il était aussi producteur de règles pour produire les règles. Le droit qui dictait les règles pour produire les règles était le droit de la Tradition. Et cette Tradition était constitutive de l'ordre juridique. Elle était « constitutionnelle».

L'enregistrement parlementaire des lois du roi représentait, dans cette conception, le pivot de toute l'organisation des pouvoirs, l'institution « qui sert de rempart à toutes les autres »,158 le vrai noyau du système. Aucune hiérarchie de normes - ni statique, ni dynamique - n'aurait pu exister sans un pouvoir ad hoc destiné à la faire vivre dans les rapports juridiques (et politiques) concrets. Tous les fils du système politique et institutionnel convergeaient dans la jurisdictio du Parlement. C'était cet organe qui faisait vivre et opérait la hiérarchie des normes ; et celle-ci faisait vivre son pouvoir, permettant la conversion de la juridiction en participation à la décision politique.

La théorie juridique de l'État, élaborée dans le milieu parlementaire et exaltée par lélan que réussit à lui donner l'avocat Le Paige, se tenait dans une indissoluble corrélation entre « loi » et « juridiction». En définitive, on pensait qu'il n'y avait pas d'État sans droit ; qu'il n'y avait pas de droit sans juridiction ; qu'il ny avait pas juridiction sans magistrature; et qu'il n'y avait pas de magistrature

154 Cf. Cocatre-Zilgien (1963: 67).

155 Le Paige (1755: 201-202).

156 Le Paige (1753-1754, II : 216).

157 Le Paige (1753-1754, II : 231).

158 BPR, $L P 539=33, \mathrm{f}^{\circ} 16$. 
sans un corps institutionnalisé de juristes autonomes par rapport au pouvoir politique du souverain.

Cette conception d'une logique rigoureuse comportait le risque d'un anéantissement de l'État monarchique absolu, dont le principe était l'unité de la souveraineté. Mais les robins étaient trop rusés pour tomber dans le piège. Ils se gardaient bien d'affirmer ouvertement la volonté de puissance politique de la magistrature. Ils ne voulaient point la responsabilité directe du pouvoir. Ils avaient besoin de la façade de la structure monarchique-absolue. Ils agissaient donc avec des instruments occultes.

C'est la raison pour laquelle la hiérarchie des normes, le principal de ces instruments d'action, était destinée à rester cachée et on ne la retrouvera jamais tant qu'on la cherchera là où elle ne pouvait point se trouver. Le pouvoir de la robe était lui aussi caché. $159 \mathrm{Il}$ préférait jouer la discrétion et laisser le système, comme le comprit génialement Mme d'Épinay, dans une permanente oscillation, suspendu au doute sur qui vraiment exerçait le pouvoir :

Il est certain que depuis létablissement de la monarchie françoise, cette discussion d’autorité, ou plutôt de pouvoir, existe entre le roi et le parlement. Cette indécision même fait partie de la constitution monarchique; car si on décide la question en faveur du roi, toutes les conséquences qui en résultent le rendent absolument despote. Si on la décide en faveur du Parlement, le roi à peu de chose près, n’a pas plus d'autorité, que le roi d'Angleterre ; ainsi, de manière ou d'autre, en décidant la question, on change la constitution de l'État. 160

Mais l'idée très aiguë de cette femme de talent, qui savait observer la réalité bien au-delà de la surface et qui ne se laissait pas éblouir par les étincelantes escarmouches des pamphlétaires qui soutenaient l'une ou l'autre faction, nétait pas trop suivie. La plupart des partisans de la thèse royaliste restaient liés de façon entêtée à l'objection classique que l'on adressait à la thèse parlementaire. C’est Le Paige lui-même qui saisit l'occasion et résume l'argument des adversaires :

Avant de finir, il est bon, Monsieur, que je vous fasse part d'une belle objection que jenten[d]s faire par des gens qui se creent fort importan[t]s. Si le roi, disent-ils, ne

159 Voir mon essai Di Donato 2001. Ce caractère occulte fut d'ailleurs la vraie raison de l'incompatibilité idéologique (au-delà des possibles alliances ou des accords partiels ou encore des ententes sous table qui sans doute se vérifièrent) entre les juristes et les philosophes des Lumières, et cela explique aussi pourquoi le premier acte de la Révolution fut l'abolition radicale des vieux parlements : cf. Carré 1912.

160 Lettre envoyée à Ferdinando Galiani le 11 avril 1771 : cf. Mémoires et correspondance de Mme d'Épinay, 3 vols., ed. Brunet, Paris 1818, t. III, lettre XII, 392-393 ; dans ce texte, cité par Carcassonne (1927 : 456-457), Mme d'Épinay tisse les louanges de l'ambiguïté du droit public français et voit en celle-ci la vraie vertu de la constitution du royaume. 
peut pas changer la forme et les loix de l'Etat, il y a donc en France deux autorités, dont l'une peut s'opposer à l'autre. Voilà le grand champ de bataille. ${ }^{161}$

La réponse de Le Paige à lépineuse question de la « diarchie » constitue un petit chef d'œuvre de l'esprit de finesse typique - dirait-on avec une expression wéberienne presque «idéal-typique »- de l’idéologie juridique d’Ancien Régime et semble ainsi la meilleure façon de prendre congé des patients lecteurs, en les laissant réfléchir sur cet éternel conflit - dont la hiérarchie des normes constituait l'instrument privilégié dans les mains de l'une des deux parties, les juristes - entre les deux corps du Léviathan:

Le roi étant toujours obligé dêtre juste, et pouvant être souvent surpris, il est nécessaire qu'il y ait dans l'Etat des ministres de la justice qui soient chargés de la lui représenter, et spécialement obligés de ne point se prêter à faire paroître juste ce qui ne le seret pas. Si le roi ne veut pas les écouter, alors il soumet l'autorité de la justice à celle de la force: s'il se rend à leurs représentations, il soumet l'autorité de la force à celle de la justice. Dans l'un et dans l'autre cas, c'est toujours le roi qui décide et qui agit; comme c'est toujours nous mêmes qui agissons, soit que nous soumettions la raison aux passions, ou les passions à la raison. ${ }^{162}$

Bibliographie

Raffaele AJELLO, 1990 : Alle origini del droit moderno: legittimazione et consenso. Formalismo medievale e moderno. Naples : Jovene.

- - 1999: L'esperienza critica del diritto. Lineamenti storici. Vol I: Le radici medievali dell'attualità. Naples : Jovene.

Paolo ALATRI, 1977 : Parlamenti e lotta politica nella Francia del Settecento. Rome-Bari: Laterza.

Michel ANTOINE, 1951 : Les comités de ministres sous le règne de Louis XV. Revue historique de droit français et étranger XXVIII (1951). 193230.

_—, 1970 : Le Conseil du Roi sous le règne de Louis $X V$. Genève-Paris : Droz.

_-, 1973 : Le Conseil royal des finances au XVIIIe siècle. Genève : Droz.

_—, 1975 : L'entourage des ministres aux XVIIe et XVIIIe siècles. Origines et histoire des cabinets des ministres en France. Michele Antoine et al. Genève : Droz. 15- 21.
_- 1986 : Le dur métier de Roi - Études sur la civilisation politique de la France d'Ancien Régime. Paris : PUF.

——, 1989 : Louis XV. Paris : Fayard.

——, 1994 : Corruption et inamovibilité des juges sous Louis XV - Un exemple bordelais (1713). Justice et justiciables - Mélanges Henri Vidal. Montpellier : Faculté de Droit, d'Économie et de Gestion de Montpellier. 239-252.

Patrick ARABEYRE, Jean-Louis HALPÉRIN, Jacques KRYNEN (Eds.), 2007 : Dictionnaire historique des juristes français $X I I^{e}-X X^{e}$ siècle. Paris : PUF.

André-Jean ARNAUD, 1977 : Le médium et le savant. Signification politique de l'interprétation juridique. Archives de Philosophie du droit (1972). Réédité dans: André-Jean Arnaud: Le droit trahi par la philosophie. Rouen : Bibliothèque du Centre d'Étude des Systèmes politiques et juridiques.

Françoise AUTRAND, 1981 : Naissance d'un grand corps de l'État - Les gens du Parlement de Paris 1345-1454. Paris : Publications de la Sorbonne.

161 BPR, $L P 539=33, \mathrm{f}^{\circ} 17$.

162 BPR, $L P 539=33$, fos $17-18$. 
Maria Stella BARBERI, 2002 : Mysterium $e$ Ministerium - Figure della sovranità. Turin : Giappichelli.

Bernard BARBICHE, 1999 : Les institutions de la monarchie française à l'époque moderne. XVIeXVIII ${ }^{e}$ siècle. Paris : PUF.

Olivier BEAUD, 1994 : La puissance de l'État. Paris : PUF (coll. « Léviathan »).

François BERTAUT DE FRÉAUVILLE, 1701: Les prérogatives de la robe. Paris: J. Le Febvre.

Hiérôme (ou même Jérôme) BIGNON, 1610 : De l'excellence des Roys et du Royaume de France. Paris : chez Hiérosme Drouart.

Bertrand BINOCHE, 2005 (Ed.) : Les équivoques de la civilisation. Seyssel : Champ Vallon.

_-, 2007 : La raison sans l'histoire. Paris : PUF.

Peter BLICKLE (Ed.), 1998 : Résistance, représentation et communauté - Les origines de l'État moderne en Europe, XIIIe-XVIII e siècle. Paris : PUF.

Wim BLOCKMANS \& Jean-Philippe GENET (Eds.), 1993 : Visions sur le développement des États européens. Théories et historiographies de l'État moderne. Rome : Editions de l'École française de Rome.

François BLUCHE, 1986 : Les magistrats du Parlement de Paris au XVIII e siècle (1715-1771). Paris : Economica.

-—, 2000 : Louis XV. Paris : Perrin.

Remo BODEI, 2000 : Le logiche del delirio - Ragione, affetti, follia. Rome-Bari : Laterza.

Richard BONNEY (Ed.), 1996 : Systèmes économiques et finances publiques - Les origines de l'État moderne en Europe, XIIIe- XVIIIe siècle. Paris : PUF.

Alain BOUREAU, 2000 : Le simple corps $d u$ roi. L'impossible sacralité des souverains français XVe-XVIIIe siècle. Paris : Les éditions de Paris.

Fernand BRAUDEL, 1993 : Grammaire des civilisations [1963]. Paris : Flammarion (coll« champs histoire ").

Elizabeth A. R. BROWN \& Richard C. FAMIGLIETTI, 1994 : The "Lit of justice": semantics, ceremonial, and the Parlement of Paris, 13001600. Sigmaringen : J. Thorbecke.

Philibert BUGNYON, 1702 : Legum abrogatarum et inusitatarum tractatus [Traicté des loix abrogées et inusitées en toutes les cours ... du royaume de France, 1563], apud Petrum de Dobbeleer, Bruxellis.

Jean-Marie CARBASSE \& Laurence DEPAMBOURTARRIDE (Eds.), 1999 : La conscience du juge dans la tradition juridique européenne, Paris : PUF.

Ely CARCASSONNE, 1927 : Montesquieu et le problème de la constitution française au XVIII e siècle. Paris : PUF.
Henri CARRÉ, 1912 : La fin des parlements (17881790). Paris : Hachette.

Ernst CASSIRER, 1993 : The Myth of the State. Oxford : Oxford University Press.

Olivier CAYLA \& Marie-France RENOUXZAGAMÉ (Eds.), 2001 : Loffice du juge: part de souveraineté ou puissance nulle? Paris : LGDJ.

Gian Mario CAZZANIGA \& Yves-Charles ZARKA (Eds.), 2001 : Penser la souveraineté à lépoque moderne et contemporaine. 2 vols. Pise-Paris : ETS-Vrin.

Philippe CHIAPPINI, 2006 : Le droit et le sacré. Paris : Dalloz.

André COCATRE-ZILGIEN, 1963 : Les doctrines politiques des milieux parlementaires dans la seconde moitié du XVIIIe siècle ou Les avocats dans la bataille idéologique prérévolutionnaire. Annales de la Faculté de Droit et des Sciences Économiques de Lille. 29-154.

Janet COLEMAN (Ed.), 1996: L'individu dans la théorie politique et dans la pratique - Les origines de l'État moderne en Europe, XIII ${ }^{e}$ XVIII ${ }^{e}$ siècle. Paris : PUF

Philippe CONTAMINE (Ed.), 1998 : Guerre et concurrence entre les États européens du XIVe au XVIII siècle - Les origines de l'État moderne en Europe, XIII ${ }^{-}-\mathrm{XVIII}^{e}$ siècle. Paris : PUF.

Pietro COSTA, 1969 : Iurisdictio - Semantica del potere politico nella pubblicistica medievale (11001433). Milan: Giuffrè.

Noël COULET \& Jean-Philippe GENET (Eds.), 1990 : L'État moderne: le droit, l'espace et les formes de l'État. Paris : Éditions du CNRS.

Robert DARNTON, 1997 : Libri proibiti Pornografia, satira e utopia allorigine della Rivoluzione francese. Milano : Mondadori. Trad. italienne du The Forbidden Best-Sellers of PreRevolutionary France. New York : Norton, 1995.

Robert DESCIMON, 1990 : Modernité et archaïsme de l'État monarchique: le Parlement de Paris saisi par la vénalité (XVIe siècle). L'État moderne: genèse bilans et perspectives. Ed. Jean-Philippe Genet. Paris : Éditions du CNRS. 147-161.

_-, 1992 : Les fonctions de la métaphore du marriage politique du Roi et de la République - France, XVe- XVIII e siècles. Annales E.S.C. (1992) 6. 1127-1147.

Furio DIAZ, 1962 : Filosofia e politica nel Settecento francese. Turin : Einaudi.

Francesco DI DONATO, 1996 : Esperienza e ideologia ministeriale nella crisi dellancien régime - Niccolò Fraggianni tra diritto, istituzioni e politica. 2 vols. Naples : Jovene.

_-, 1997 : Constitutionnalisme et idéologie de robe - Lévolution de la théorie juridico-politique de Murard et Le Paige à Chanlaire et Mably. Annales (1997) 4. 821-852. 
_- 1998 : Un costituzionalismo di antico regime? Prospettive socio-istituzionali di storia giuridica comparata. Lo spirito delle istituzioni. Esperienze costituzionali nella Francia moderna. Denise Richet. Rome-Bari : Laterza. VII- L.

_—, 1998b : Genova e Napoli - Immagini dell'ideologia togata nel confronto tra due modelli socioistituzionali. Genova, 1746: una città di antico regime tra guerra e rivolta. Eds. Carlo Bitossi \& Claudio Paolocci. Genova ; Archivio di Stato di Genova - Quaderni Franzoniani. 727-788.

_-, 2001 : La puissance cachée de la robe L'idéologie du jurisconsulte moderne et le problème du rapport entre pouvoir judiciaire et pouvoir politique. Loffice du juge: part de souveraineté ou puissance nulle? Eds. Olivier Cayla \& Marie-France Renoux-Zagamé. 89-116.

_-, 2002 : Critica della ragione virtuosa - Roland Mousnier : la civiltà giuridica dello Stato assoluto. La costituzione nello Stato assoluto. Diritto, società, istituzioni in Francia dal Cinquecento al Settecento. Roland Mousnie. Naples : ESI. XVCXXXII.

_- 2003 : L'ideologia dei robins nella Francia dei Lumi - Costituzionalismo e assolutismo nell'esperienza politico-istituzionale della magistratura di antico regime (1715-1788). Naples : ESI.

__, 2003b : Le concept de « représentation » dans la doctrine juridico-politique de Louis-Adrien Le Paige. Le concept de représentation dans la pensée politique: actes du Colloque d'Aix-en-Province, Mai 2002 - AFHIP XV. Aix-en-Provence : PUAM. 53-73.

——, 2003c : Giuristi e storia dello Stato: il conflitto magistratura-potere politico nella Francia del Settecento. Storia Amministrazione Costituzione. Annale ISAP (2003) 11. Bologna: Il Mulino. 73122.

——, 2004 : Il giudizio di costituzionalità nella Francia dell'ancien régime: una storia politicoistituzionale. I. I fondamenti teorico-pratici. Giornale di Storia Costituzionale I (2004) 7. 147165.

——, 2005 : Il giudizio di costituzionalità nella Francia dell'ancien régime: una storia politico-istituzionale. II. Le dinamiche della prassi. Giornale di Storia Costituzionale I (2005) 9. 65-86.

——, 2006 : De la médiation patriarcale à la médiation bureaucratique. Considération sur le " gouvernement des juges ». Larchitecture $d u$ droit - Mélanges en l'honneur du Professeur Michel Troper. Eds. Pierre Brunet et al. Paris : Economica. 387-406.

_—, 2007 : La revisione costituzionale in una prospettiva storico-istituzionale - Il problema del mutamento giuridico in relazione al mutamento sociale e culturale. La revisione costituzionale $e$ i suoi limiti - Fra teoria costituzionale diritto interno esperienze straniere. Eds. Silvio Gambino \& Guerino D’Ignazio. Milan: Giuffrè. 555-578.

Roger DOUCET, 1948a : Les institutions de la France au XVIe siècle. t. I, Les cadres géographiques. Les institutions centrales et locales. Paris : A. e J. Picard.

_- 1948b : Les institutions de la France au XVIe siècle. t. II. La seigneurie. Les services publics. Les institutions ecclésiastiques. Paris: A. e J. Picard.

Guillaume DU VAIR, 1641 : Euvres. S. Cramoisy Paris 1641 (rist. anast. Slatkine, Genève 1970).

Maurice DUVERGER, 1987 : Les constitutions de la France. Paris : PUF.

École Française de Rome, 1991 : Théologie et droit. Théologie et Droit dans la science politique de l'État moderne. Actes de la table ronde de Rome (12-14 novembre 1987). Roma : École Française de Rome (Collection de l'École Française de Rome, 147).

Norbert ELIAS, 1973 : Über den Prozess der Zivilisation. Frankfurt am Main : Suhrkamp.

Allan ELLENIUS (Ed.), 2001 : Iconographie, propagande et légitimation - Les origines de l'État moderne en Europe, XIII - XVIII siècle. Paris : PUF.

Louis FAVOREU (et al.), 2003 : Droit constitutionnel. Paris : Dalloz.

Domenico FELICE (Ed.), 2001-2002 : Dispotismo Genesi e sviluppi di un concetto filosofico-politico. 2 vols. Naples : Liguori.

Luigi FERRAJOLI, 2004 : La sovranità nel mondo moderno - Nascita e crisi dello Stato nazionale. Roma-Bari : Laterza.

Julian H. FRANKLIN, 1993 : Jean Bodin and the rise of absolutist theory. Cambridge : Cambridge University Press.

Gian Mario CAZZANIGA \& Yves-Charles ZARKA (Eds.), 2001 : Penser la souveraineté à l'époque moderne et contemporaine. Actes des Colloques (Pisa 1-3 giu. 2000 e Paris 2-4 nov. 2000). 2 vol. Pise-Paris : ETS-Vrin.

Jean-Philippe GENET (Ed.), 1990 : L'État moderne: genèse bilans et perspectives. Actes du Colloque tenu à Paris (19-20 sett. 1989). Paris : Éditions du CNRS.

Jean-Philippe GENET \& Michel LE MENÉ (Eds.), 1987 : Genèse de l'État moderne - Prélèvement et Redistribution. Actes $d u$ colloque de Fontevraud 1984. Paris : Éditions du CNRS.

Ralph GIESEY, 1961 : The Juristic Basis of Dynastic Right to the French Throne. Transactions of the American Philosophical Society 51 (1961) 5. 3-47.

_- 1987a : Le roi ne meurt jamais : les obseques royales dans la France de la Renaissance. Paris : Flammarion. 
_-1987b : Cérémonial et puissance souveraine. France XVe-XVIIe. Paris : Colin.

-_2004 : Rulership in France, 15th-17th centuries. Aldershot: Ashgate Variorum.

Éric GOJOSSO, 1999 : Le contrôle de l'activité normative royale à la veille de la Révolution : l'opinion de Mercier de la Rivière. Revue de la Recherche Juridique (1999) 1. 237-250.

_- 2001 : Le contrôle de constitutionnalité des lois dans quelques écrits monarchistes de la période révolutionnaire. La constitution dans la pensée politique. Actes du Colloque de Bastia (7-8 septembre 2000). Aix-en-Provence : PUAM. 229-243.

_-, 2002 : Le contrôle de constitutionnalité dans la pensée juridique française de la seconde moitié du XVIIIème siècle : une autre approche. Giornale di Storia Costituzionale. 2 (2002) 4. 145-154.

Christine GOUZI, 2007 : L’Art et le jansénisme au XVIIIe siècle. Paris : Nolin.

Simone GOYARD-FABRE, 1989 : Jean Bodin et le droit de la Republique. Paris : PUF.

Vincenzo GUIZZI, 1969 : Il diritto comune in Francia nel XVIII secolo. Tijdschrift voor Rechtsgeschiedenis - Revue d'histoire du droit XXXVII (1969). 1-46.

Pierre HADOT, 2006 : Éloge de la philosophie antique. Paris : Éditions Allia.

Albert N. HAMSCHER, 1987 : The Conseil Privé and the Parlements in the Age of Louis XIV: A Study in French Absolutism. Transactions of the American Philosophical Society 77 (1987) 2.

__, 1989 : L’héritage de la Fronde: les Conseils du Roi et l'autorité judiciaire des Parlements pendant le règne personnel de Louis XIV. La Fronde en question. Actes du Dix-huitième Colloque du Centre Méridional de Rencontres sur le XVIIe siècle. Eds. Roger Duchêne \& Pierre Ronzeaud. Aix-en-Provence : Publications de l'Université de Provence.

Sarah HANLEY, 1991 : Le "Lit de Justice " des Rois de France - L'idéologie constitutionnelle dans la légende, le rituel et le discours. Trad. André Charpentier. Paris : Aubier.

Jean-Louis HAROUEL, Jean BARBEY, Eric BOURNAZEL \& Jacqueline THIBAUT-PAYEN, 1987 : Histoire des institutions de lépoque franque à la Révolution. Paris : PUF.

Robert JACOB, 1996 (Ed.) : Le juge et le jugement dans les traditions juridiques européennes Études d'histoire comparée. Actes du colloque international (Paris 16-18 set. 1993). Paris : LGDJ.

_-, 2001 : Judicium et le jugement. Lacte de juger dans l'histoire du lexique. Loffice du juge: part de souveraineté ou puissance nulle? Eds. Olivier
Cayla \& Marie-France Renoux-Zagamé. Paris : LGDJ. 35-71.

Ernst Hartwig KANTOROWICZ, 1989 : The King's two Bodies - A Study in Medieval Political Theology (1957). Princeton : Princeton University Press.

Jacques KRYNEN, 1993 : L'empire du roi - Idées et croyances politiques en France. XIIIe- XVe siècle. Paris : Gallimard.

_-, 2000 : Qu'est-ce qu'un Parlement qui représente le roi? Excerptiones iuris: Studies in Honor of André Gouron. Eds. Laurent Mayali \& Bernard Durand. Berkeley : The Robbins Collection (Studies in Comparative Legal History ). 353366.

_-, 2001 : Une assimilation fondamentale: le Parlement 'Sénat de France'. A Ennio Cortese. Eds. Italo Birocchi \& Domenico Maffei. Rome : Il Cigno. 208-223.

_—, 2002 : Le droit : une exception aux savoirs du prince. Le savoir du Prince. Du Moyen Âge aux Lumières. Ed. Ran Halévi. Paris : Fayard. 51-67.

Jacques KRYNEN \& Albert RIGAUDIÈRE (Eds.), 1992 : Droits savants et pratiques françaises $d u$ pouvoir (XIe- XVe siècles). Bordeaux : Presses Univ. De Bordeaux.

Bernard DE LA ROCHE FLAVIN, 1617 : Treize livres des parlements de france, es quels est amplement traite de leur origine et institution, et des presidents, conseillers, gens du roi, greffiers, secretaires, huissiers et autres officiers. Millanges, Bourdeaus 1617 (= BNF, LF25-1).

Antoine LÉCA, 1987 : Les grandes étapes du contrôle de constitutionnalité des lois dans la pensée politique européenne d'Aristote à Kelsen. Revue de la Recherche juridique (1987) 3. 957-979.

André LEMAIRE, 1907 : Les lois fondamentales de la monarchie françaises, d'après les théoriciens de l'Ancien Régime. Paris : Fontemoing.

Louis-Adrien LE PAIGE, 1753-1754 : Lettres historiques sur les fonctions essentielles du Parlement; sur le droit des Pairs, et sur les loix fondamentales du Royaume. 2 vols. aux dépens de la Compagnie, Amsterdam [mais Paris] rispett. I, 1753; II, 1754 (= BNF, LD-4. 2563; BPR, LP 534=29 et $L P$ 2133-2135).

-—, 1754b : Lettre apologétique, critique et politique sur l'Affaire du Parlement. s. 1. [Paris] 1754 (= BPR, Lett. 329).

-, 1755 : Principes sur le gouvernement monarchique. Londres : chez Jean Nourse.

_—, 1756 : Lettre sur les lits de justice. s.l.n.d. [Paris 1756].

---, 1771 : Principes avoués et défendus par nos pères. Institutions que nous sommes dans l'immense impuissance de changer. Lit de justice de 
1770 et édit de février 1771, s.l.n.d. [mais Paris, Enclos du Temple 1771] : Bibliothèque de la Société de Port-Royal, $L P$ 815=1 (in $12^{\circ}$ ). Autre exemplaire des Principes: BNF, LB38-1202.

Matthew LEVINGER, 1990 : La rhetorique protestataire du parlement de rouen (1753-1763). Annales E.S.C. (1990) 3. 589-613.

Charles LOYSEAU, 1608 : Traité des seigneuries. Paris : chez Abel L'Angelier.

Claire LOVISI-SAGUEZ, 1983 : Les lois fondamentales au XVIIIe siècle - Recherches sur la loi de dévolution de la couronne. Paris : PUF.

Catherine Laurence MAIRE, 1998 : De la cause de Dieu à la cause de la Nation - Le jansénisme au XVIIIe siècle. Paris : Gallimard.

Louis MARIN, 1981 : Le portrait du roi. Paris : Les éditions de Minuit.

Jeffrey W. MERRICK, 1990 : The Desacralization of the Monarchy in the Eighteenth Century. Baton Rouge/London : Louisiana State University Press.

Jean-Louis MESTRE, 1992 : Lévocation d'un contrôle de constitutionnalité dans les « Maximes du Droit public français" (1775). L'Europe et l'État. Actes du Colloque de Toulouse (1-13 apr. 1991). Aix-en-Provence : PUAM. 21-36.

Jean MONTAIGNE, 1512 : Tractatus celebris de auctoritate et præminentia sacri magni consilii et parlamentorum regni Franciae. Parisiis 1512 (= BNF, RES-LF22-1).

Roland MOUSNIER, 1947 : Le Conseil du Roi de la mort de Henri IV au gouvernement personnel de Louis XIV. Etudes d'histoire moderne et contemporaine (1947) 1. Réimpression in: La plume, la faucille et le marteau - Institutions et société en France du Moyen Age à la Révolution. Roland Mousnier. Paris : PUF.

_-, 1970a : La plume, la faucille et le marteau Institutions et société en France du Moyen Age à la Révolution. Paris : PUF.

_—, 1970b : Le Conseil du Roi de Louis XIII à la Révolution. Paris : PUF.

_-, 1971 : La vénalité des offices sous Henri IV et Louis XIII. Paris : PUF.

-_, 1974-1980: Les institutions de la France sous la monarchie absolue. 2 vols., I. Société et État. II. Les organes de l'État et la société. Paris : PUF.

-_, 2002: La costituzione nello Stato assoluto. Diritto, società, istituzioni in Francia dal Cinquecento al Settecento. Naples : ESI.

Jean NAGLE, 2008 : Un orgueil français. La vénalité des offices sous l'Ancien Régime. Paris: Odile Jacob.

François OLIVIER-MARTIN, 1948 : Histoire $d u$ droit français des origines à la Révolution. Paris : Domat Montchrestien.
-—, 1988 : Les Parlements contre l'absolutisme traditionnel au XVIII siècle. Paris : Éditions Loysel. __, 1997a : Les lois du Roi. Paris : LGDJ.

_—, 1997b : L'absolutisme français. Paris : LGDJ.

Antonio PADOA SCHIOPPA (Ed.), 2000 : Justice et législation - Les origines de l'État moderne en Europe, XIII - XVIIIe siècle. Paris : PUF.

_-, 2003 : Il ruolo del diritto nella genesi dello Stato moderno: modelli, strumenti, princìi. Studi di Storia del Diritto (vol. II). Milan : Giuffrè. 25-77.

Étienne PASQUIER, 1560-1567 : Des recherches de la France. Editio princeps chez V. Sertenas, Paris 1560 (pour le livre I) ; et chez P. Trepperel, Orléans 1567 (pour le livre II). [Les principales et successives éditions de cette œuvre sont (toutes imprimées à Paris) respectivement chez: P. L'Huillier, 1569; C. Micard, 1571; G. Robinot, 1581; L. Sonnius, 1607 e 1621; O. de Varennes, 1633; P. Ménard, 1643; G. de Luynes 1665 ; enfin, dans les Euvres, aux dépens de la Compagnie, Amsterdam 1723, 2 vols. in folio].

Philippe PAYEN, 1997 : Les arrêts de règlement $d u$ Parlement de Paris au XVIII siècle - Dimension et doctrine. Paris : PUF.

-_, 1999 : La physiologie de l'arrêt de règlement $d u$ Parlement de Paris au XVIIIe siècle. Paris : PUF.

Vincenzo PIANO MORTARI, 1962 : Diritto romano e diritto nazionale in Francia nel secolo XVI. Milan : Giuffrè.

_-, 1977 : La formazione storica del diritto moderno francese: dottrina e giurisprudenza del secolo XVI. La formazione storica del diritto moderno in Europa: atti del Terzo Congresso Internazionale della Società Italiana di Storia del Diritto. Vol. I. Firenze : Olschki. 195-219. Réimpression in: Itinera juris - Studi di storia giuridica dell'Età moderna. Naples: Jovene, 1991.

_—, 1980 : Tradizione romanistica e tradizione giuridica europea nella Francia del secolo XVI. Il diritto comune e la tradizione giuridica europea. Perugia : Libreria universitaria editrice. 67-78. Réimpression in: Itinera juris - Studi di storia giuridica dell'Età moderna. Naples: Jovene, 1991

_—, 1989 : L'ordo juris nel pensiero dei giuristi francesi del secolo XVI. Clio - Rivista trimestrale di studi storici (1989). 245-267. Réimpression in: Itinera juris - Studi di storia giuridica dell'Età moderna. Naples: Jovene, 1991.

_-, 1991 : Itinera juris - Studi di storia giuridica dell'Età moderna. Naples: Jovene.

Sophie PETIT-RENAUD, 2001: "Faire loy » au Royaume de France. De Philippe VI à Charles V (1328-1380). Paris : De Boccard. 
Diego QUAGLIONI, 1992 : I limiti della sovranità: il pensiero di Jean Bodin nella cultura politica e giuridica dell'eta moderna. Padoue : CEDAM.

-—, 2004 : La sovranità. Rome-Bari : Laterza.

Jacques RANCIÈRE, 1995 : La Mésentente - Politique et philosophie. Paris : Galilée.

Wolfgang REINHARD (Ed.), 1996 : Les élites du pouvoir et la construction de l'État en Europe Les origines de l'État moderne en Europe, XIIIXVIIIe siècle. Paris : PUF.

Marie-France RENOUX-ZAGAMÉ, 2003 : Du droit de Dieu au droit de l'Homme. Paris : PUF (coll. "Leviathan »).

Denis RICHET, 1973 : La France moderne: l'esprit des institutions. Paris : Flammarion.

Albert RIGAUDIÈRE, 1994 : Histoire du droit et des institutions. Paris : Éditions C. D.

_-, 2003 : Penser et construire l'État dans la France du Moyen Age. XIII - XVe siècle. Paris : Comité pour l'Histoire économique et financière de la France.

——, 2004 : Un rêve royal français: l'unification du droit. Académie des Inscriptions et des BellesLettres. Comptes rendus des séances de l'année 2004. Paris : De Boccard.

John M. G. ROGISTER, 1995 : Louis XV and the 'Parlement' of Paris, 1737- 1755. Cambridge : Cambridge University Press.

Ettore ROTELLI, 2008 : Le costituzioni di democrazia. Testi 1689-1850. Bologne : Il Mulino.

Anne ROUSSELET-PIMONT, 2005 : Le chancelier et la loi au XVIe siècle. D'après l'œuvre d'Antoine Duprat de Guillaume Poyet et de Michel de l'Hospital. Paris : De Boccard.

Claire SAGUEZ-LOVISI, 1984 : Les Lois fondamentales au XVIIIe siècle: recherches sur la loi de dévolution de la couronne. Paris : PUF.

François SAINT-BONNET, 2001 : Le Parlement, juge constitutionnel $(\mathrm{XVI}-\mathrm{XVIII}$ ) ) siècle. Droits (2001) 34. 177- 97.

François SAINT-BONNET \& Yves SASSIER, 2004 : Histoire des institutions avant 1789. Paris : Montchrestien.

Wolfgang SCHMALE, 1987 : Les parlements et le terme de constitution au XVIII e siècle en France : une introduction. Il pensiero politico XX (1987) 3. 415-424.

_-, 1990 : Du droit d'Ancien Régime aux droits de l'homme: la continuité et la rupture. Il pensiero politico XXIII (1990) 1. 108-116.

Claude de SEYSSEL, 1519: La Grant' Monarchie de France. Paris : Regnault Chauldiere.

Jean-Fabien SPITZ, 1998 : Bodin et la souveraineté. Paris : PUF.

Jean STAROBINSKI, 1989 : Le mot « civilisation ». Le Temps de la Réflexion (1983) 4. Réimpression in: Le remède dans le mal. Critique et légitimation de l'artifice à l'âge des Lumières. Paris : Gallimard. Joseph Reese STRAYER, 1970 : On the Medieval Origins of the Modern State. Princeton: Princeton University Press.

Philippe SUEUR, 1993 : Histoire du droit public français. XVe- XVIIIe siècle. La genèse de l'État contemporain. 1 / La constitution monarchique. 2. ed. Paris : PUF.

-—, 1994 : Histoire du droit public français. XVeXVIII e siècle. La genèse de l'État contemporain. 2 / Affirmation et crise de l'État sous l'Ancien Régime. 2. ed. Paris : PUF.

Julian SWANN, 1995 : Politics and the 'Parlement' of Paris under Louis XV, 1754- 1774. Cambridge: Cambridge Univ. Press.

Alberto TENENTI, 1987 : Stato: un'idea, una logica - Dal comune italiano allassolutismo francese. Bologna : Il Mulino.

Michel TROPER, 1994 : Pour une théorie juridique de l'État. Paris : PUF.

_-, 1996 : La forza dei precedenti e gli effetti perversi del diritto. Ragion pratica (1996) 6. 65-75.

---, 1998 : Per una teoria giuridica dello Stato. Naples : Guida (Strumenti e ricerche). Trad. italienne de Troper 1994.

_-, 1999 : Una teoria realista dell'interpretazione. Materiali per una storia della cultura giuridica XXIX (1999) 2. 473-493.

-_, 2001 : La théorie du droit, le droit, l'État. Paris : PUF.

——, 2003 : La philosophie du droit. Paris : PUF (coll. "Que sais-je »)

_-, 2005 : Théorie des contraintes juridiques. Eds. Michel Troper, Véronique Champeil-Desplats, Christophe Grzegorczyk. Paris : LGDJ.

Dale Kenneth VAN KLEY, 1984: The Damiens Affair and the Unraveling of the Ancien Régime, 1750 1770. Princeton : Princeton University Press.

_- 2002 : Les origines religieuses de la Révolution française. 1560-1791. Trad. Alain Speiss. Paris : Seuil.

Arnaud VERGNE, 2006 : La notion de constitution d'après les cours et assemblées à la fin de l'Ancien Régime (1750-1789). Paris : De Boccard.

Gabrielle VILAR-BERROGAIN, 1958 : Guide des recherches dans les fonds d'enregistrement sous l'Ancien Régime. Paris : Imprimerie Nationale.

Michel VILLEY, 2003 : La formation de la pensée juridique moderne [1961-1964]. Paris : PUF (Coll. "Léviathan »).

Pierre WACHENHEIM, 1998 : L'image de Louis $\mathrm{XV}$ à travers l'estampe séditieuse et satirique. Imaginaire et métier artistique à Paris sous l'Ancien Régime. Ed. Daniel Rabreau. Paris/ 
Bordeaux : Annales du Centre Ledoux. t. II. 87102.

__, 2001a : Le thème du crible dans l'estampe - Les avatars d'une composition satirique récurrente. Dix-Huitième Siècle (2001) 33. 457-480.

_-, 2001b : Un héros éphémère sous le règne de Louis XV - Labbé Chauvelin, ou portrait du sapajou en Grand Homme. L'Art et les normes sociales au XVIII ${ }^{e}$ siècle. Eds. Thomas W. Gaehtgens et al. Paris : Centre Allemand d'Histoire de l'Art, MSH.

-—, 2004 : Art et politique, langage pictural et sédition dans l'estampe sous le règne de Louis $\mathrm{XV}$. Thèse in 2 vol. soutenue sous la direction de Daniel Rabreau. Université de Paris I PanthéonSorbonne, UFR d'Histoire de l'art et d'archéologie.

_—, 2005 : Un exemple de revendication identitaire au XVIIIe siècle : le recueil Godonnesche ou l'histoire métallique du Parlement. Identités, appartenances, revendications identitaires (XVIe-XVIII siècles). Eds. Marc Belissa et al. Paris : Nolin. 163-190.

——, 2006 : L'iconographie polémique des parlementaires sous le règne de Louis XV. Revue d'Histoire des Facultés de Droit et de la Science juridique (2006) 25-26. 7-70.
Yves-Charles ZARKA (Ed.), 1996 : Jean Bodin : nature, histoire, droit et politique. Paris : PUF.

Gaston ZELLER, 1948 : Les institutions de la France au XVIe siècle (1987). 2. ed. Paris: PUF.

Manuscrits et fonds d'archives. Bibliothèque du Sénat:

- Extrait des choses les plus importantes qui se sont passées au Parlement - 1719-1746, par Guy Nouet, fos. $246 r-v$. et suiv. (= Bibliothèque du Sénat, au Palais du Luxembourg, fonds Boissy d'Anglas 799 [9260]).

- Recueil de Traittés [sic] de droit public. Différentes matières; $\mathrm{t}$. V, $\mathrm{f}^{\circ} 34$ (= Bibliothèque du Sénat, $m s$. n. 21 [8932]).

Manuscrits et fonds d'archives. Bibliothèque nationale de France :

- Monumens précieux de la sagesse de nos rois (= BNF, F-25312-25313).

- Proposition faicte en la Court de Parlement de Rouen par Noble Homme et saige, Messire François Olivier, Chevalier, Chancelier de France, le Roy present, Tenant audict lieu son Siege Royal de Iustice, le huitiesme iour d'Octobre, 1550, Rouen 1551 (= BNF, inv. Lf-25. 127). 
